\title{
REVIEW
}

\section{Hormones and the hippocampus}

\author{
R Lathe \\ Centre for Genome Research and Centre for Neuroscience, University of Edinburgh, West Mains Road, Edinburgh EH9 3JQ, UK \\ (Requests for offprints should be addressed to R Lathe, Centre for Genome Research, King's Buildings, West Mains Road, Edinburgh EH9 3JQ, UK; \\ Email: rlathe@ed.ac.uk)
}

\begin{abstract}
Hippocampal lesions produce memory deficits, but the exact function of the hippocampus remains obscure. Evidence is presented that its role in memory may be ancillary to physiological regulation. Molecular studies demonstrate that the hippocampus is a primary target for ligands that reflect body physiology, including ion balance and blood pressure, immunity, pain, reproductive status, satiety and stress. Hippocampal receptors are functional, probably accessible to their ligands, and mediate physiological and cognitive changes. This argues that an early role of the hippocampus may have been in sensing soluble molecules (termed here 'enteroception') in blood and cerebrospinal fluid, perhaps reflecting a common evolutionary origin with the olfactory system ('exteroception').
\end{abstract}

Functionally, hippocampal enteroception may reflect feedback control; evidence is reviewed that the hippocampus modulates body physiology, including the activity of the hypothalamus-pituitary-adrenal axis, blood pressure, immunity, and reproductive function. It is suggested that the hippocampus operates, in parallel with the amygdala, to modulate body physiology in response to cognitive stimuli. Hippocampal outputs are predominantly inhibitory on downstream neuroendocrine activity; increased synaptic efficacy in the hippocampus (e.g. long-term potentiation) could facilitate throughput inhibition. This may have implications for the role of the hippocampus and long-term potentiation in memory.

Journal of Endocrinology (2001) 169, 205-231

\section{The hippocampus and memory}

Attention has focused on the hippocampus in view of its likely role in memory encoding and its dysfunction in Alzheimer's disease. The hippocampal formation undoubtedly contributes to the encoding of long-term memories, but an exclusive focus on memory would be a mistake. The present review emphasises an important aspect of hippocampal function: that of responding to and governing body physiology. What follows briefly revisits the role of the hippocampus in learning and memory, and the electrophysiological correlates of memory processes, before considering how the spectrum of genes expressed in the hippocampal formation may cast light on the involvement of the hippocampus in other processes. (In this paper, 'hippocampus' and 'hippocampal formation' are used interchangably to denote the juxtaposition of the fields of the cornu ammonis with the dentate gyrus.)

\section{Memory and the hippocampus}

The hippocampus, located beneath the cerebral hemispheres, resembles a large 'wishbone' (the curved
Y-shaped bone in the chicken neck), but takes its name from the appearance of its arms in cross-section - the interlocking double-U formed by the tightly aligned cell bodies of ammon's horn (cornu ammonis) and the dentate gyrus - reminiscent of the shape of Hippocampus spp. (Fig. 1; for detailed reviews of hippocampal structure see Amaral 1987, Amaral \& Witter 1989). Memory problems in a patient with limbic damage (i.e. at the edge of the forebrain) were first recorded in 1898; another 60 years elapsed before the hippocampus was pinpointed as playing a special role. The remarkable individual, ' $\mathrm{H}$ M', underwent bilateral hippocampectomy to alleviate severe epilepsy; he was found subsequently to have lost all ability to remember recent events, although immediate working memory, recall of long-distant events and skill learning generally remained intact (Scoville \& Milner 1957). Similar findings were reported in other patients at the time (Stepien \& Sierpinski 1964). Memory impairment associated with Alzheimer's disease also reflects early dysfunction of the hippocampus (Carlesimo \& Oscar-Berman 1992). These and other data argue that the primate hippocampus plays a pivotal role in declarative or episodic memory processes required for event learning and recall 

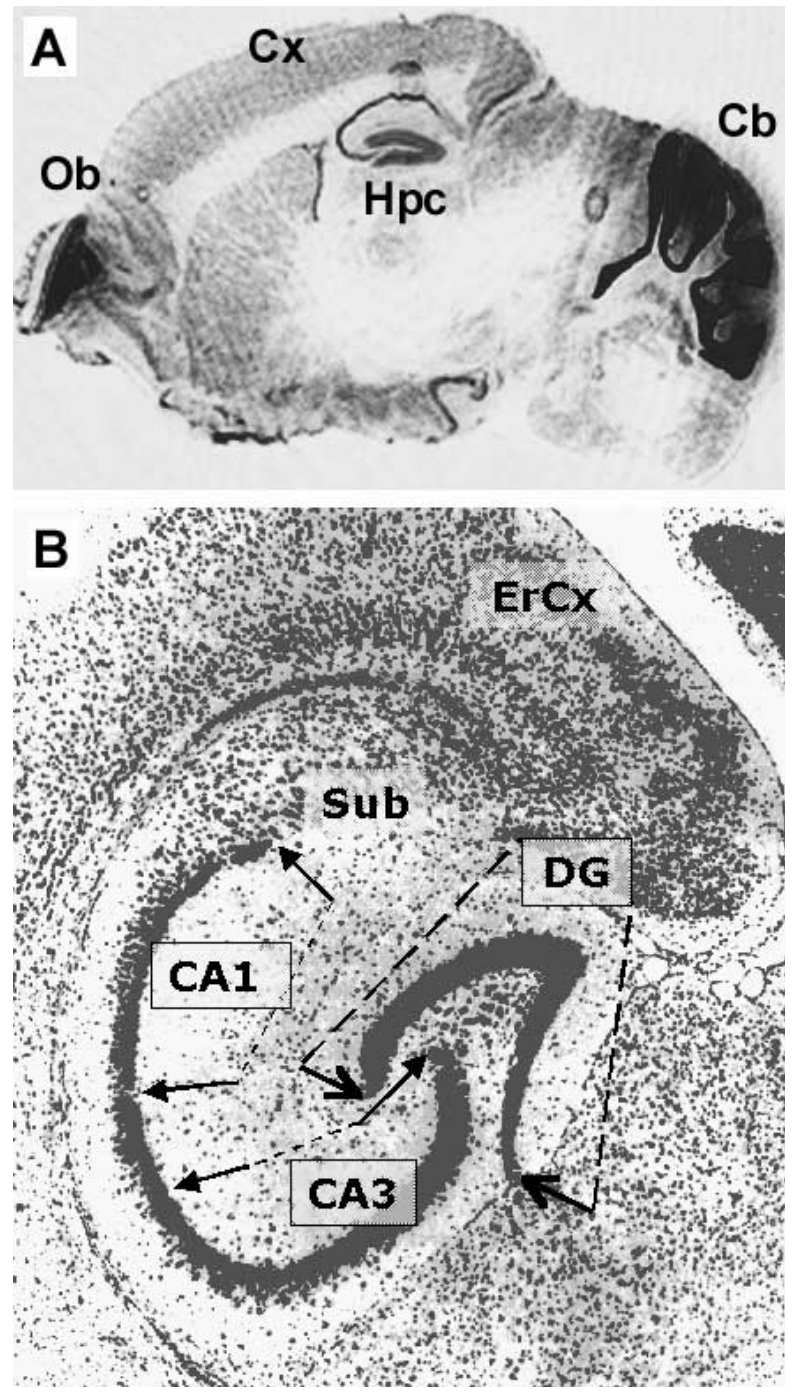

Figure 1 Cross-section of the mouse brain and hippocampus. (A) Sagittal section of mouse brain; $\mathrm{Cb}$, cerebellum; $\mathrm{Cx}$, cortex; $\mathrm{Hpc}$, hippocampus; Ob, olfactory bulb. (Courtesy of K Rose.) (B) Cresyl violet stain of a horizontal section of 33-day-old mouse brain subregion containing the hippocampus. CA1, CA3, regions of the cornu ammonis; CA2 (not labelled) is the small area separating CA1 and CA3; DG, dentate gyrus; ErCx, entorhinal cortex; Sub, subiculum. (Original photomicrograph (markings overlaid) from Angevine (1965), (C) Academic Press, with permission.)

(Squire 1992, Eichenbaum et al. 1992). Similar conclusions have been reached in rodents, in which damage to the hippocampus can lead to failure to remember the location of a hidden platform in the water maze (Morris et al. 1982, 1986, Morris 1989), a task believed to reflect declarative memory processes. (For the distinction between declarative and procedural (skill learning) memory, and equally, between the explict/implict and episodic/ semantic divisions of memory, see Cohen \& Eichenbaum

1993, Tulving \& Markowitsch 1998.) Because hippocampal lesions do not eradicate previously established memory traces, the hippocampus could be a temporary store for information, particularly spatial information, that is subsequently encoded in other cortical regions (Marr 1971, Willshaw \& Buckingham 1990, Recce \& Harris 1996).

Two electrophysiological phenomena provide further insights into the role of the hippocampus. Firstly, some neurones in the rodent hippocampus fire according to the location or orientation of the animal (O'Keefe \& Conway 1978, O'Keefe \& Nadel 1978, O'Keefe 1979). These 'place cells' appear to process spatial information and could in some way provide instructions as to the spatial location of the animal. This theory is by no means generally accepted (Cohen \& Eichenbaum 1991). Secondly, hippocampal synapses display a robust and easily measured form of stimulus-dependent plasticity that could underlie some memory processes. Long-term potentiation (LTP; a sustained increase (often a doubling) in the efficacy of transmission at a synapse or group of synapses) can be elicited experimentally by a short train of high-frequency stimuli; potentiation can persist for days in the intact animal (Bliss \& Gardner-Medwin 1973, Bliss \& Lømo 1973). Artificial depolarisation of the downstream neurone concurrently with firing of the upstream neurone ("pairing') also brings about robust potentiation at their synaptic junction (Jaffe \& Johnston 1990, Lin et al. 1993, Magee \& Johnston 1997). This would appear to fulfil the criteria of a learning device as proposed by Hebb (1949): hippocampal LTP has been widely conjectured to be the molecular embodiment of a temporary memory trace (Bliss \& Collingridge 1993). This is supported by the impairment of spatial learning in rats that is produced by pharmacological blockade of LTP (Morris et al. 1986) and by studies on LTP-impaired transgenic animals (Chen \& Tonegawa 1997). Despite this mass of data, the case for a link between hippocampal LTP and memory is very much circumstantial.

Although the hippocampus may contribute to learning and memory, particularly in tasks demanding spatial navigation, memory processing is but one of a long list of diverse functions attributed to the formation. The hippocampus is likely to contribute to attention, arousal and emotional states, including stress; disorders associated with the hippocampus include not only memory deficits but also anxiety, delusional disorders, depression, epilepsy, and schizophrenia. Furthermore, the hippocampus contributes to adaptive and reproductive behaviour, including maternal care. (For general overviews of the functions ascribed to the hippocampal formation see, in particular, Douglas 1967, Squire et al. 1989, Eichenbaum et al. 1992, Jarrard 1995.) The specific computational task that the hippocampus performs is unknown, but it is abundantly clear that its role is not restricted to memory processing. Heretically, 
memory formation could even be secondary to its central function, so far obscure.

\section{Genes expressed in the hippocampus}

Much of what we know about the function of the hippocampus derives from lesion studies, including pharmacological, surgical, and genetic lesions. An alternative approach is beginning to yield some insights; this has involved the inspection of genes expressed in the hippocampal formation. Although the brain is known to express a greater fraction of the genome than other tissues (Hahn \& Laird 1971, Bantle \& Hahn 1976, Milner \& Sutcliffe 1983), one study suggested that the hippocampus might be a particularly rich site of gene expresssion. Random insertion of a reporter gene into the mouse genome was combined with analysis of hippocampal expression of the reporter: $37 \%$ of insertions (95\% confidence interval 21 to 59\%; 22 lines studied) were found to be expressed in the hippocampus (Steel et al. 1998), suggesting that more than one-third of protein-coding genes are expressed here. Three such genes were examined, all were membraneassociated polypeptides with likely signalling roles (Steel et al. 1998). In another study, one random gene isolated on the basis of hippocampus-enriched expression was found to encode an enzyme responsible for local metabolism of adrenal steroids (Stapleton et al. 1995, Rose et al. 1997). Together these findings prompt the suggestion that the hippocampus might express an unusually high proportion of receptors and ancillary signalling molecules.

To address this, a survey was carried out. This confirmed an unusual density and diversity of receptor expression in the hippocampus. Expression was demonstrated either directly (in situ hybridisation, immunohistochemistry, ligand uptake) or indirectly (e.g. by effects on synaptic plasticity in slices or on neurite outgrowth in hippocampal cultures). Over and above the expected targets for neurotransmitters and neuropeptides, the spectrum of receptors present in the hippocampus includes, for illustration, binding sites, activities, or both, for basic ions and metabolites, steroids, prostaglandins, lymphokines, blood control factors, immune system components, hypothalamic releasing hormones, and growth, reproductive and gastrointestinal hormones. Table 1 gives a list of more than 60 ligands with binding sites/receptors identified in the hippocampus.

It should not be inferred that the hippocampus is, inevitably, the primary site of receptor expression. Many receptors are found in several brain regions, particularly the hypothalamus, cortical areas, the amygdala, and the olfactory bulb. For others, however, expression appears to be most robust in the hippocampal formation. For example, the luteinising hormone (LH) receptor is expressed at greatest density in the cornu ammonis regions and the dentate gyrus (Lei et al. 1993); binding sites for insulin and insulin-like growth factors (IGFs)-I and -II show a marked preference for the hippocampus (Lesniak et al. 1988, Marks et al. 1990, 1991, Couce et al. 1992, Doré et al. 1997), whereas binding of peripherally administered $\left[{ }^{3} \mathrm{H}\right]$ corticosterone demonstrates that the mineralocorticoid receptor is very substantially restricted to, if not almost exclusively located in, the hippocampus (Fig. 2), although there is expression, at lower levels, in the hypothalamus and amygdala.

At first glance, this apparent complexity of receptor expression in the hippocampus could be a simple experimental artefact. The close alignment of neuronal cell bodies in the hippocampus could increase the sensitivity of detection of gene expression by in situ staining, affinity or hybridisation techniques; what appears to be selectively present in the hippocampus might not be specific at all. Several lines of evidence argue against this explanation. Firstly, the pattern of expression of each gene is distinct some express robustly in cornu ammonis region CA1 but at undetectable levels in the adjacent dentate gyrus where the neuronal alignment is equally tight; others show the reverse pattern. Secondly, in several cases the additional abundance in the hippocampus has been verified by techniques insensitive to the stacking density of the neuronal cell bodies, such as northern hybridisation, or by binding and immunological studies after dissection. Two examples illustrate this: 1) hippocampal punches showed greater binding of ligands targeting either mineralocorticoid receptor or glucocorticoid receptor $\left(\left[{ }^{3} \mathrm{H}\right]\right.$ aldosterone and $\left[{ }^{3} \mathrm{H}\right]$ dexamethasone) per mg total protein than did punches from other brain regions (Magarinos et al. 1989); 2) binding of $\left[{ }^{125} \mathrm{I}\right]$ insulin, $\left[{ }^{125}\right.$ I]IGF-I or -II, and [ ${ }^{125}$ I]interleukin 1 (IL-1), normalised to tissue protein, was generally greater in the dentate gyrus than in any other region with the possible exception of the piriform cortex (Ban 1994, Doré et al. 1997). Table 2 presents a list of some important hormone/ligand binding sites that are present in great or greatest abundance in the hippocampus (see also Fig. 2).

\section{Accessibility and functionality of hippocampal receptors}

The question arises, are the ectopically expressed receptors in the hippocampus accessible to ligands present in blood or cerebrospinal fluid (CSF), and are they functionally coupled to downstream signal transducing mechanisms? In terms of accessibility, the hippocampus could be well positioned to receive soluble ligands from blood or CSF, lying alongside the choroid plexus with its rich blood supply and immediately adjacent to the cerebral ventricles. Adjacent brain regions may be equally well placed to receive soluble ligands, but the positioning of the hippocampus alongside the brain ventricles appears to be conserved in evolution. There is evidence, furthermore, to suggest that many ligands can gain access to the 


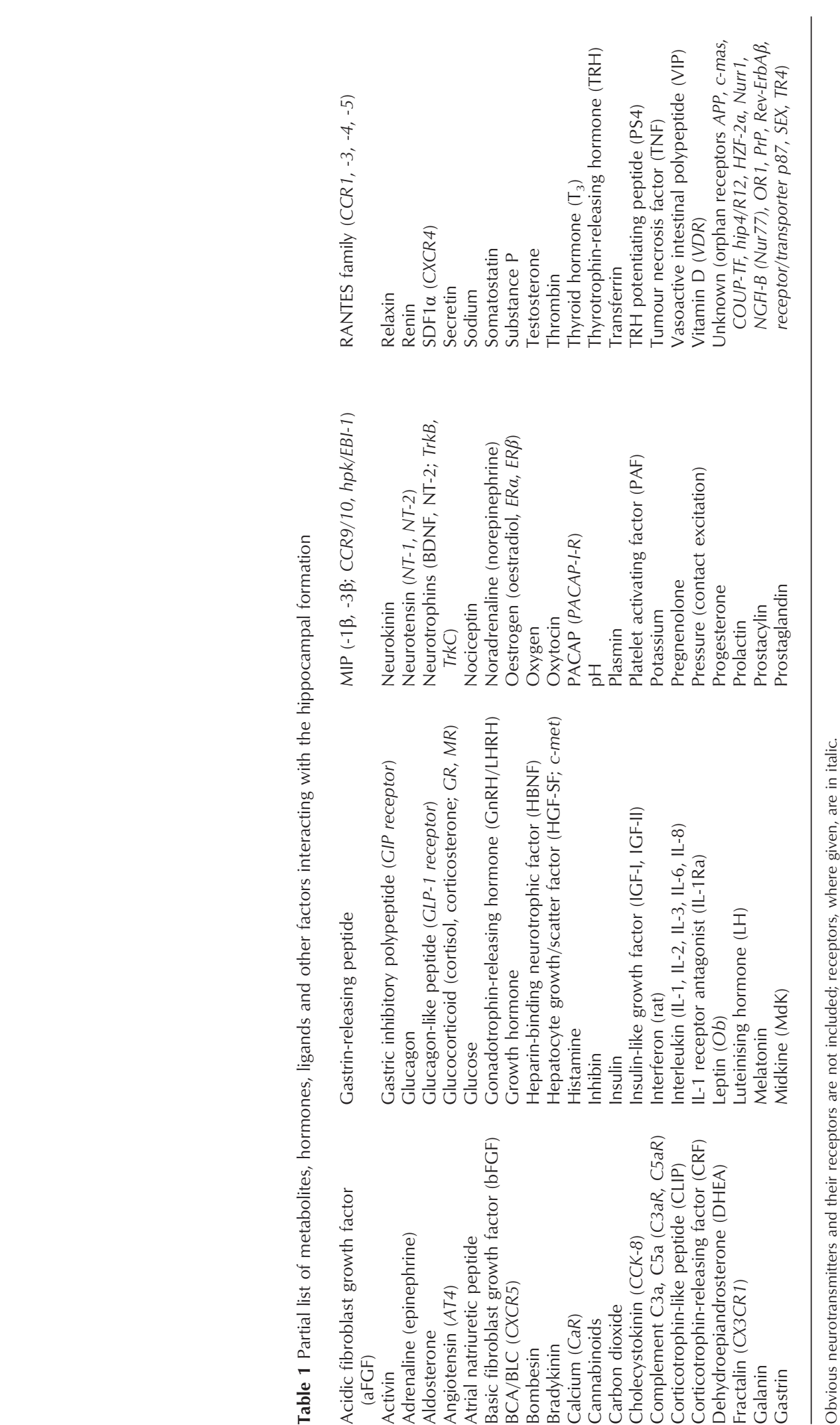



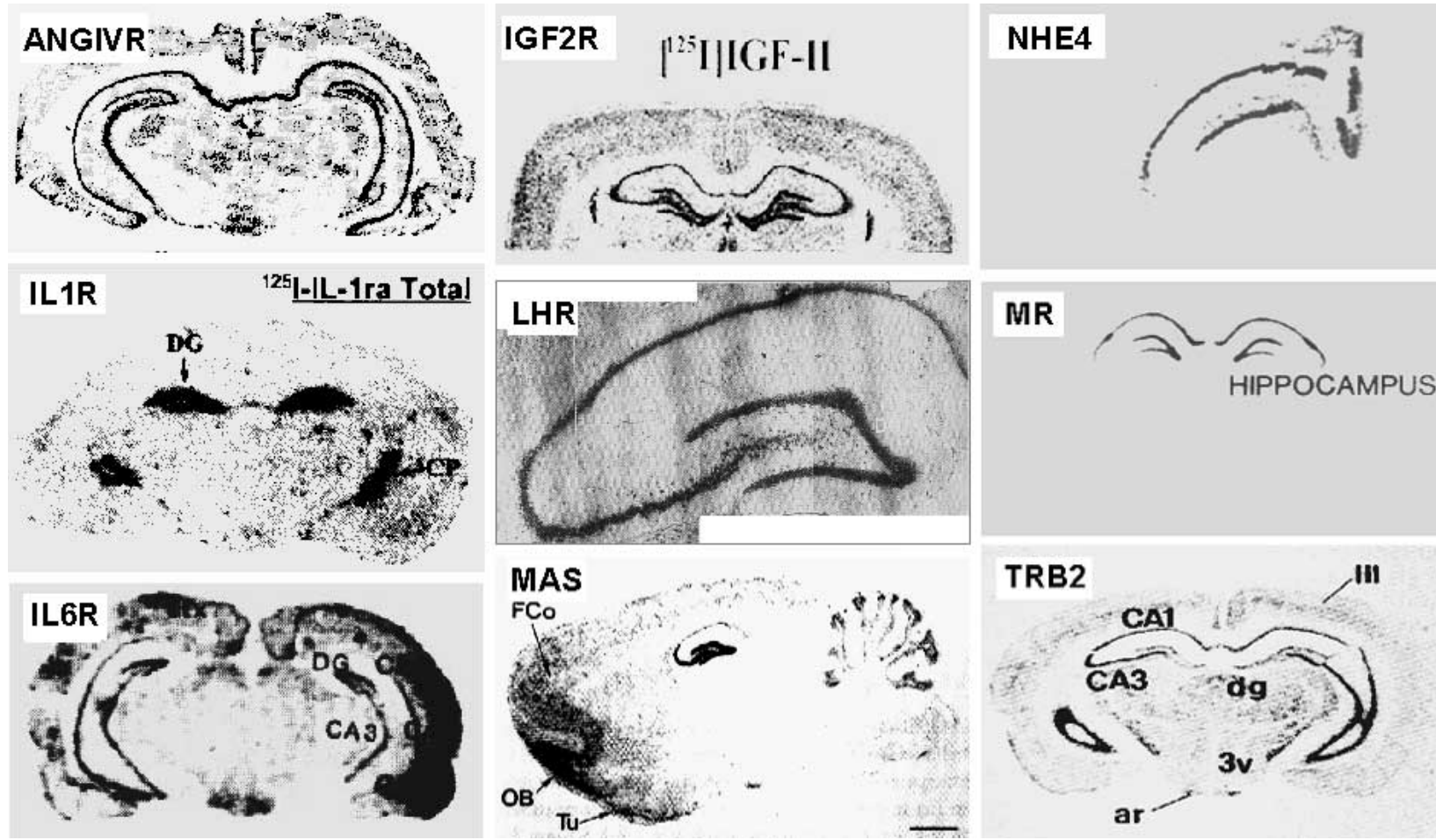

Figure 2 Localised expression of receptors and binding sites for blood hormones in the hippocampus. The selection of brain binding sites is intended to be representative but is subservient to the availability and quality of in situ studies presented in the literature. ANGIVR: In situ binding of ${ }^{125}$ I-Ang IV to guinea pig brain. Greatest binding density is to regions CA $1-3$ and the dentate gyrus (DG), with significant binding in the medial habenula, cortex, thalamus, and cerebellum. (Reproduced from Fig. 1 of Wright et al. (1993), (C) Pergamon, with permission.) IGF2R: Binding of $\left[{ }^{125}\right.$ I]IGF-II to rat brain. Binding was recorded principally in the hippocampus (regions CA1-3 and dentate gyrus (DG)) and cortex. (Reproduced from Fig. 2 in Doré et al. (1997), (C) IBRO/Elsevier, with permission.) NHE4: In situ hybridisation of rat brain to a probe specific for the sodium-hydrogen exchanger NHE4 reveals selective expression in regions CA1-3 of the hippocampus, but not the dentate gyrus. (Reproduced from Fig. 6 in Bookstein et al. (1996), (C) The American Physiological Society, with permission.) IL1R: Binding of [ $\left.{ }^{125} \mathrm{I}\right]-\mathrm{IL}-1$ receptor antagonist to mouse brain. Greatest binding recorded was to the hippocampus (principally the dentate gyrus) and choroid plexus, with significant diffuse binding in the cortex. (Reproduced from Fig. 5 of Takao et al. (1992), (C) Elsevier, with permission.) A very similar pattern was observed with binding of $\left[{ }^{125} \mathrm{I}\right]-\mathrm{IL}-1$ to mouse brain sections (Takao et al. 1992; Ban et al. 1994). LHR: In situ hybridisation to female rat brain using a probe specific for the LH receptor. Levels of expression in brain are greatest in the hippocampus and dentate gyrus, some expression was also detected in other brain regions, including cerebellum, brainstem, hypothalamus, choroid plexus and ependymal cells of the ventricles. (Reproduced from Fig. 7 in Lei et al. (1993), (C) The Endocrine Society, with permission.) MR: Autoradiography of brain of adrenalectomised rat labelled in vivo with $\left[{ }^{3} \mathrm{H}\right]$ corticosterone. Binding is predominantly to mineralocorticoid receptor located in hippocampal CA regions and dentate gyrus. (Reproduced from Fig. 2 in de Kloet (1991), (C) Academic Press, with permission.) Mineralocorticoid receptor expression is also present in the hypothalamus, choroid plexus and brainstem (see de Kloet 1991). IL6R: In situ hybridisation to rat brain with a probe specific for the IL-6 receptor. mRNA was present at greatest abundance in the hippocampus (regions CA1-3 and dentate gyrus), cerebellum and olfactory system, with scattered positive cells in the cortex and hypothalamus. (Reproduced from Fig. 2 in Schöbitz et al. (1993), (C) European Neuroscience Association, with permission.) MAS: In situ hybridisation of rat brain to a probe specific for c-mas, a potential but unconfirmed angiotensin receptor. Strong labelling was exclusively linked to the dentate gyrus, hippocampal regions CA1-4, olfactory tubercle (medial part; Tu), piriform cortex and the olfactory bulb (OB), with diffuse staining in the cortex; apparent cerebellar expression is due to non-specific effects. (Reproduced from Fig. 3 in Bunnemann et al. (1990), (C) Elsevier, with permission.) TRB2: In situ hybridisation to rat brain with a probe specific for the thyroid hormone receptor type $\beta-2$. mRNA was most abundantly detected in the hippocampus (regions CA1-3 and dentate gyrus (dg)), cerebellum, hypothalamus and brainstem, with diffuse cortical staining. (Reproduced from Fig. 4 in Li \& Boyages (1996), (C) The Endocrine Society, with permission.)

hippocampus and, in a number of cases, it is the primary brain binding site.

Peripherally administered corticosterone accumulates, in brain, very selectively in the hippocampus (panel MR in Fig. 2); however, it may be unsurprising that small molecules such as steroids can traverse the blood-brain barrier (BBB; Herbert 1986). Nevertheless, larger peptide or polypeptide ligands seem able to cross into the brain, including insulin, ILs $-1,-2$ and -6 , immunoglobulin, and a number of neurotrophins (Pardridge et al. 1985, Zlokovic et al. 1990b, Banks et al. 1991, 1994, 1995, Banks \& Kastin 1991, Martin et al. 1992, Waguespack et al. 1994, 
Table 2 Key ligands, binding sites and receptors enriched in the hippocampus

\begin{tabular}{|c|c|}
\hline & Hormone/ligand/binding site \\
\hline \multicolumn{2}{|l|}{ Primary physiological parameter } \\
\hline Blood pressure & Angiotensin IV (AT4) \\
\hline \multirow[t]{2}{*}{ Blood ion balance } & Calcium (extracellular calcium receptor, CaR) \\
\hline & $\begin{array}{l}\text { Osmolarity? Sodium? (sodium-hydrogen exchanger, } \\
\text { NHE4) }\end{array}$ \\
\hline Infection and immunity & Interleukin 2 \\
\hline Pain & Nociceptin \\
\hline \multirow[t]{3}{*}{ Reproductive status (also Growth) } & Androgens \\
\hline & Oestrogen $(E R \alpha, E R \beta)$ \\
\hline & Luteinising hormone \\
\hline \multirow[t]{2}{*}{ Satiety (Growth) } & Acidic fibroblast growth factor \\
\hline & Insulin; insulin-like growth factors \\
\hline Stress & Glucocorticoids (MR, GR) \\
\hline
\end{tabular}

ER, MR, GR, oestrogen, mineralocorticoid and glucocorticoid receptor respectively.

Poduslo \& Curran 1996). Peripherally administered chorionic gonodotrophin $\left({ }^{125} \mathrm{I}-\mathrm{hCG}\right)$ can cross the BBB to bind selectively to $\mathrm{LH}$ receptors within the hippocampal formation (Lukacs et al. 1995); a similar result has been obtained with ${ }^{125}$ I-prolactin (J Russell, personal communication). Specialised polypeptide transporter systems have been suggested (reviewed by Herbert 1986; see also Meisenberg \& Simmons 1983); specific transporters have been documented for arginine-vasopressin (AVP; Zlokovic et al. 1990a) and for the Tyr-MIF-1 (encephalin, dynorphin) family (Reed et al. 1994). Furnished with these examples it seems prudent to assume that many blood- (and CSF-) borne ligands can gain access to binding sites in the brain, prominently in the hippocampus, either by diffusion or by facilitated transport.

Are these receptors functional? Taking a single measure of bioactivity, the modulation of synaptic plasticity (including LTP) in hippocampal slices, almost without exception those hormones and ligands that have been studied produce significant effects. These ligands include (the list is not exhaustive): activin, angiotensin, basic fibroblast growth factor, cholecystokinin (CCK), corticosterone, corticotrophin-like peptide, oestrogen, histamine, interferon, IL-1 $\beta$, IL-2, IL-6, melatonin, plasmin, somatostatin, thyroid hormone, and tumour necrosis factor. One may conclude that the receptors are functionally coupled to signal transducing machinery. A similar conclusion was discussed by Sanes \& Lichtman (1999).

\section{Mediation of functional changes in vivo: adrenal and gonadal steroids}

There is a further caveat. Binding to hippocampal receptors and modulation of excitability or LTP induction argue for, but do not prove, in vivo functionality. Nevertheless, there is abundant evidence that peripherally synthesised receptor ligands can modulate brain function and behaviour. This is borne out by a series of examples, described below, that illustrate the diversity and possible physiological significance of ligand interactions with hippocampal receptors. The first two examples concern steroids synthesised from the adrenal and gonads.

Glucocorticoids Corticotrophin-releasing factor (CRF) released from the hypothalamus in response to stress stimulates the pituitary to secrete adrenocorticotrophin $(\mathrm{ACTH})$ that, in turn, directs the adrenal gland to secrete stress hormones (noradrenaline, adrenaline, and glucocorticoids). The principal circulating glucocorticoid in rodent, corticosterone (cortisol in human), targets receptors throughout the body, but also in the brain. Two principal types of glucocorticoid receptor have been described. The first, termed the mineralocorticoid receptor in view of its affinity for aldosterone in addition to corticosterone, is selectively and abundantly expressed, in brain, in the hippocampal neurones (see Fig. 2); $\left[{ }^{3} \mathrm{H}\right]$ aldosterone and $\left[{ }^{3} \mathrm{H}\right]$ dexamethasone show greater binding to hippocampal tissue than to other brain regions (Magarinos et al. 1989). The mineralocorticoid receptor has high affinity for glucocorticoids and, under resting conditions, is largely complexed to ligand. The homologous glucocorticoid receptor is widely expressed throughout the brain, including the hippocampus (Aronsson et al. 1988, McGimsey et al. 1991, Van Eekelen \& de Kloet 1992), but has lower affinity for glucocorticoids, such that it becomes occupied only under stress conditions accompanied by increased glucocorticoid concentrations (reviewed by de Kloet 1991). In addition to these nuclear receptors, there is strong evidence for a second type of receptor at the cell surface, so far uncharacterised, that mediates fast non-genomic actions of corticoids (including aldosterone) on neuronal excitability (Orchinik et al. 1991, Wehling et al. 1993, Iwasaki et al. 1997, Joels 1997). Note that, within the hippocampus, there are subtle and intriguing differences in the patterns of expression of glucocorticoid receptors between rat, hamster and human (Sutanto et al. 1988, Seckl et al. 1991). 
Glucocorticoids modulate neuronal function in the hippocampus Glucocorticoids can impair hippocampal LTP in vitro (Dubrovsky et al. 1987, Pavlides et al. 1993), as well as increasing afterhyperpolarisation mediated by smallconductance calcium-activated potassium channels (SK channels) (Joels \& de Kloet 1989) that have been implicated in arousal. Because of the 'inverted-U' response to these hormones (Diamond et al. 1992), low concentrations maintain, moderate concentrations promote, and high concentrations impair neuronal function. LTP is dependent on adrenal output in vivo, and adrenalectomy results in a significant decrease in the extent of LTP (Shors et al. 1990). Conversely, stress and excess glucocorticoids impair neuronal function and survival in the formation, and hippocampal-dependent memory (reviewed by Sapolsky et al. 1986, Filipini et al. 1991, de Kloet 1991, Kerr et al. 1994, McEwen \& Sapolsky 1995, Lupien \& McEwen 1997, de Kloet et al. 1998). However, glucocorticoid regulation is complex. Circulating concentrations change systematically through the light/dark cycle and adrenalectomy modifies the circadian dimorphism of hippocampal LTP (Dana \& Martinez 1984). In rats, in vivo LTP was most easily elicited duing the hours of darkness whereas, after adrenalectomy, reversal was reported - LTP could be readily induced during daylight hours, but only with difficulty during darkness (Dana \& Martinez 1984).

Gonadal steroids Gonadal steroids also target the hippocampus and modulate neuronal activity. In rat brain, immunohistochemical staining with androgen receptor antibodies revealed androgen receptor localisation in several rat brain regions, including hypothalamus, amygdala, septum, hippocampus, and cortex (Sar et al. 1990, Bingaman et al. 1994), confirming the findings of earlier studies using tritiated ligand binding. In situ hybridisation demonstrated comparable levels in hippocampus and hypothalamus, with hippocampal expression being predominently in CA1 (Kerr et al. 1995). In rhesus monkey, androgen receptor immunoreactivity was recorded in hypothalamus, arcuate nucleus, amygdala and hippocampus, where positive nuclei are distributed widely in cornu ammonis regions CA1-3 and the dentate gyrus (Choate et al. 1998).

Regarding oestrogen targets, Maggi et al. (1989) reported that a monoclonal antibody against the breast cancer cell line oestrogen receptor detected greater immunoreactivity in the rat hippocampus than in other brain regions tested, except perhaps the hypothalamus, where immunoreactivity was comparable to that found in hippocampus; after oestradiol benzoate treatment of ovariectomised animals, immunoreactivity was significantly greater in the hippocampus than in the hypothalamus (Maggi et al. 1989). This study was complicated by the fact that in situ hybridisation reveals $\operatorname{ER} \beta$ to be the principal oestrogen receptor (ER) species in the hippocampus, and that receptor mRNA was present in a variety of brain regions at greater concentrations than in the hippocampus (Shughrue et al. 1997a,b, 1998). However, studies with conjugated oestradiol have shown that the steroid, like the glucocorticoids, also binds to unidentified cell-surface receptors (Zheng \& Ramirez 1997), the distribution of which is unknown. Oestradiol also modulates hippocampal LTP (e.g. Cordoba Montoya \& Carrer 1997) and neuronal activity in the hippocampus both in vivo and in vitro (not reviewed here; see McEwan \& Alves 1999).

\section{Mediation of functional changes in vivo: further examples}

Modulation of hippocampal function and behaviour is not restricted to steroids, and the following examples 1-7 support the conclusion that diverse ligands and hormones, as suggested by the prominent expression of receptors, can target the hippocampus and modify behaviour. These include molecules contributing to reproduction (LH), blood pressure (angiotensin), glucose regulation and satiety (insulin, acidic fibroblast growth factor (aFGF)), immunity (IL-2), pain (nociceptin), and ion sensing (the extracellular $\mathrm{Ca}^{2+}$ receptor and, potentially, the sodium-hydrogen exchanger, NHE4). In these cases, receptor activation has been shown, or is likely, to manifest itself in altered neuronal electrophysiology in the hippocampus and, in some cases, to be associated with altered memory function.

1. Luteinising hormone In both males and females, gonadal function is governed, in part, by the action of two reproductive hormones, follicle-stimulating hormone (FSH, follitropin) and LH (lutropin), released from the pituitary in response to gonadotrophin-releasing hormone $(\mathrm{GnRH})$, also known as LH releasing hormone (LHRH). In males, FSH is required for spermatid maturation, whereas LH augments testosterone production. In females, development of the ovarian follicle is determined by the patterns of FSH and $\mathrm{LH}$ production in response to pulsatile release of $\mathrm{GnRH}$. Follicular maturation is stimulated by FSH secreted in response to an increase in the frequency of $\mathrm{GnRH}$ pulses, whereas the LH surge that precipitates ovulation is brought about by a combination of increased GnRH pulse frequency and increased oestradiol secreted from the maturing follicle. In the brain, as far as can be assessed, FSH receptors are absent; in contrast, LH receptors are well expressed. The LH receptor is expressed in rat brain at greatest density in the cornu ammonis regions and the dentate gyrus, as demonstrated by in situ hybridisation, immunocytochemistry and hormone binding (Lei et al. 1993) (see Fig. 2), although transcripts were also present in hypothalamus, cerebellum and brainstem, but at lower levels (Lei et al. 1993). The LH receptor is coupled to the production of cAMP (Ji \& Ji 1991), an intracellular messenger the pivotal role of which in controlling neuronal excitability in hippocampus is well established. As noted earlier, the LH homologue hCG can cross the BBB 
(Lukacs et al. 1995); LH has not been studied in this respect. LH can modulate neuronal activity in the hippocampus (Gallo et al. 1972), although the effects of LTP have not been studied. Peripheral administration of hCG not only changes wakefulness and associated behaviours and the levels of LH receptors in hippocampus (Toth et al. 1994), but also modifies performance in a number of tests designed to elucidate hippocampal function (Lukacs et al. 1995). In the female, the presence of $\mathrm{LH}$ receptors in the brain, but the absence of receptors for FSH, would be consistent with inferred differential biological advantages of signalling to the brain either the early stages of egg development mediated by FSH or the release of an unfertilised egg under LH control. Together, these data argue that LH selectively targets the hippocampus, modifies neuronal excitability therein, and can thereby modulate hippocampal function and downstream behaviours.

2. Angiotensin Imaging reveals that several brain regions, including the hippocampus, are activated during blood pressure challenges (Corfield et al. 1995, Harper et al. 1998) and may therefore respond to homeostatic hormones including the renin/angiotensin-system. Renin is released from the kidney in response to a decrease in blood pressure, and activates circulating angiotensinogen to the decapeptide angiotensin (Ang I) by proteolytic cleavage of the inactive precursor. Ang I is subsequently processed by a number of enzymes, including the angiotensin converting enzyme (ACE) to generate a variety of Ang peptides including the octapeptide Ang II, the septapeptide Ang III and the hexapeptide Ang IV. Although not demonstrated, the smaller size of Ang IV could facilitate passage across the BBB. In turn, angiotensins act peripherally and centrally at dedicated angiotensin receptors to restore blood pressure, predominantly by modulating kidney fluid resorbtion, but also via central responses including thirst. Angiotensin receptors AT1, 2 and 4 are widely distributed. In brain, in situ hybridisation demonstrated that the AT1A and AT1B Ang II receptors are expressed in the hippocampus and other brain regions, as confirmed by binding of radiolabelled Ang II (Jöhren \& Saavedra 1996). The AT2 receptor is present in several brain regions, but not significantly in the hippocampus (Lenkei et al. 1997). In contrast, the atypical AT4 receptor that binds Ang IV with high affinity is robustly expressed in the hippocampus and a number of other brain regions, including the cortex and cerebellum; of 13 brain regions, the hippocampus exhibited the second greatest binding density of ${ }^{125} \mathrm{I}-\mathrm{Ang} \mathrm{IV}$; this was exceeded only by the cerebellum (Harding et al. 1992, Miller-Wing et al. 1993, reviewed by Wright \& Harding 1997) (see Fig. 2). Although not confirmed, angiotensin receptor modulatory activity has been attributed to the c-mas oncogene (Wolf \& Neilson 1992); c-mas is also robustly expressed in the hippocampus (Fig. 2). Ang II was reported to depress synaptic potentiation in the dentate gyrus (Denny et al. 1991, Wayner et al. 1993); studies with Ang IV have not been reported. Cognitive effects are suggested by studies describing improved task performance in hypertensive patients receiving the ACE inhibitor captopril, independent of normalisation of blood pressure (Sudilovsky et al. 1988). In rats, intracerebroventricular infusion of Ang IV, but not of Ang II, was reported to improve retention of a passive avoidance task (Wright et al. 1993), and an Ang IV analogue was shown to counteract the disruption of spatial learning induced by scopolamine (hyoscine; Pederson et al. 1998). However, the multiplicity of ligands and receptors complicates analysis; ACE may be involved in processing neuropeptides in addition to angiotensin(s), and local blood flow changes may also contribute to the process. Nevertheless, the evidence suggests that the angiotensins, production of which is governed by blood pressure, can modify neuronal communication in the hippocampus, and behaviour.

3. Insulin On release from pancreatic beta cells in response to an increase in blood glucose, insulin promotes hepatic glycogen synthesis and inhibits gluconeogenesis, whereas in adipose tissue it reduces lipolysis. The insulin receptor is prominently expressed in the hippocampus, with comparable expression in the olfactory bulb and cerebellum (Marks et al. 1991), and the insulin receptor substrate IRS-1 (which acts downstream of the receptors for both insulin and the related IGFs-I and -II) is robustly expressed in both hippocampus and olfactory bulb (Baskin et al. 1994). As seen earlier, insulin can cross the BBB whereas, in the regions examined, the binding of insulin to brain regions was greatest to the hippocampus, with the possible exception of the adjacent piriform cortex. More generally, binding sites for insulin and IGFs-I and -II show a preference for the hippocampus (Lesniak et al. 1988, Marks et al. 1991, Couce et al. 1992, Doré et al. 1997), although high levels of ${ }^{125}$ I-labelled ligand binding were observed throughout the olfactory bulb, cortex, hippocampus and choroid plexus, and some in the cerebellum (Hill et al. 1988, Bondy et al. 1992, Kar et al. 1993, Doré et al. 1997). Several studies have suggested that brain insulin, in particular, can have effects on neuronal excitability and memory. In vitro, insulin has been reported to depress the activity of hippocampal neurones (Palovcik et al. 1984) and was neuroprotective in a model of stroke (Strong et al. 1990), arguing that insulin regulates hippocampal function. In support of these findings, diabetic rats are impaired in both the establishment of hippocampal LTP and in hippocampus-dependent spatial learning (Biessels et al. 1998), but this does not distinguish between specific signalling by insulin/glucose and loss of glucose control (in this instance) leading to neuronal dysfunction; note that increases in blood glucose can improve memory performance (Gold et al. 1986, Hall \& Gold 1986), and that memory problems can be encountered in diabetic patients (Prescott et al. 1990, Hershey et al. 1997). In the 
former patient study, memory impairments were proportional to duration of illness but there was no discernible relation to degree of glycaemic control, possibly suggesting that the memory effects are unrelated to systemic glucose concentrations and implying a more direct effect of insulin. Kamal et al. (1999) showed that incubation of hippocampal slices in glucose-free medium impaired LTP, but they attributed this to reduced release of glutamate; they argue that LTP changes in diabetic rats (Biessels et al. 1998) are due to chronic disturbances of glucose control (Kamal et al. 1999). The possible involvement of insulin as a direct mediator was not examined in these studies. On balance, the data argue that insulin can target the hippocampus and that memory alterations may partly reflect this targeting. Electrophysiological and memory studies with IGFs-I and -II have not been reported.

4. Interleukin 2 Lapchak et al. (1991) recorded ${ }^{125} \mathrm{I}-$ IL-2 binding sites only in the hippocampal formation and cerebellum. In situ hybridisation revealed that the IL-2 receptor $\beta$ is prominently expressed in the hippocampus, with intense staining in the cornu ammonis regions and dentate gyrus (Petitto \& Huang 1994); IL-2 receptor $\gamma$ is also expressed here (Pettito et al. 1998). These interleukins are also able to traverse the $\mathrm{BBB}$ to gain access to the hippocampus (see earlier), where IL-2 has a variety of neurotrophic and regulatory functions, and has been reported to influence sleep and arousal, HPA axis activity, and memory (Hanisch \& Quirion 1995). At the electrophysiological level, IL-2 modulates calcium currents in hippocampal neurones (Plata-Salaman \& ffrench-Mullen 1993) and suppresses LTP (Tancredi et al. 1990, Cunningham et al. 1996). Learning and memory were impaired in mice with a targeted disruption of the the IL-2 gene (Pettito et al. 1999). It has also been reported that patients receiving IL-2 infusion experience significant cognitive effects (Walker et al. 1996). These reports together suggest that IL-2, both peripheral and locally produced, can gain access to the brain, wherein it modulates LTP and memory.

In addition to IL-2, two other interleukins (ILs-1 and -6) are also reported to target the hippocampus and impair LTP and memory. Receptor targets for both are prominently expressed in the hippocampus (Cunningham et al. 1991, Wong \& Licinio 1994, Schöbitz et al. 1993), where they inhibit LTP (Katsuki et al. 1990, Cunningham et al. 1996, Li et al. 1997, Bellinger et al. 1993); some IL-1 effects may be dependent upon vagal nerve stimulation that can release IL-1 locally in the brain.

\section{Acidic fibroblast growth factor and satiety aFGF} is synthesised by ependymal cells lining the cerebral ventricles and is released into the CSF in response to an increase in blood glucose. CSF concentrations increase 1000-fold after feeding or blood glucose increase, and aFGF has been proposed as an endogenous satiety sub- stance (Hanai et al. 1989). aFGF appears in a number of brain regions, including the hippocampus and lateral hypothalamus (Hanai et al. 1989). Expression of the FGF receptor FGFR-1 is particularly high in the hippocampus and cerebellum. FGFR-2 mRNA is found in the choroid plexus, corpus callosum and olfactory bulb, FGFR-3 mRNA is expressed diffusely throughout the brain (Yazaki et al. 1994), and FGFR-4 is expressed selectively in the medial habenular nucleus (Miyake \& Itoh 1996). In the hypothalamus, aFGF is believed to suppress feeding, but the role in hippocampus is unknown. However, subcutaneous (s.c.) infusion of aFGF directs a dosedependent increase in hippocampal synaptic potentiation, and the extent of CA1 LTP in response to tetanus was almost doubled in aFGF-treated animals (Oomura et al. 1997). It was also reported that glucose administration $2-3 \mathrm{~h}$ prior to testing resulted in some enhancement in spatial navigation skills, and this was blocked by antibody to aFGF, suggesting that aFGF mediates, in part, the effects on navigation (Oomura et al. 1993, 1997). Significantly perhaps, chronic intermittent administration of aFGF (s.c. once a week for 9 months) resulted in significant increases in aFGF receptor density in the hippocampus, but not in other brain regions (Oomura et al. 1997). Although caution is warranted in the interpretation of these experiments, it does appear that aFGF released in response to glucose can modulate neuronal activity in the hippocampus.

aFGF is not alone. The glucose-responsive hormones insulin (example 3 above) and glucagon have central effects via blood glucose, but also through direct interactions. In addition, other factors including leptin, leptinregulated polypeptides, and CCK are also implicated in satiety regulation (Ahima et al. 1996, Friedman \& Halaas 1998, Baldwin et al. 1998, Inui 1989). Leptin binding sites and receptor mRNA are prominent in the hypothalamus, hippocampus and choroid plexus, and in the olfactory system (Huang et al. 1996, 1997, Hakansson et al. 1998, Williams et al. 1999). CCK potentiates depolarisation of hippocampal neurones (e.g. Dahl \& Li 1994), and rats lacking the CCK-A receptor display impaired learning and memory (Nomoto et al. 1999). It is not known whether leptin modulates LTP and memory.

6. Nociceptin and pain The amnesic patient, H M, had marked impairments in pain perception (Hebben et al. 1985); this could be no more than coincidental, but another patient (N A) also displayed amnesia and unresponsiveness to pain after brain injury (Teuber et al. 1968). Although the lesion in N A did not affect the hippocampus, there was considerable disruption to major brain inputs and outputs of the hippocampal region such as the fornix and the mammillothalamic tract (Squire \& Moore 1979). These two cases could suggest a possible link between memory function and pain perception; hippocampectomy has been discussed in relation to pain relief (Gol \& Faibisch 1966). 
Generally, the hippocampus is not recognised as being central to pain sensitivity, and a large number of brain regions are believed to be involved in such perception, including the periaqueductal grey, the locus coeruleus, and several thalamic and limbic structures (Willis \& Westlund 1997). Injections of carbachol into a wide variety of brain regions can suppress nociception (Klamt \& Prado 1991), and electrical stimulation at many brain sites can produce reductions in pain sensitivity. However, interpretation of such studies is complicated by interfering factors. For instance, electrical stimulation at many brain sites is aversive and could thus be expected to affect nociception. In one study, only stimulation of the dorsal hippocampus and the pretectal area affected nociception without being aversive (Prado \& Roberts 1985), suggesting that the hippocampus may make a particular contribution to pain awareness. Injection of the local anaesthetic lignocaine into the dentate gyrus reduced pain scores (McKenna \& Melzack 1992), whereas painful stimuli produce changes in hippocampal neuronal activity and blood flow. At barely detectable levels of pain, regional blood flow (rBF) was increased only in restricted cortical areas of human volunteers. With increasing stimulus intensity, widespread rBF increases were recorded, not only in the cortex, but also in the contralateral hippocampus and thalamus; in contrast, rBF in the amygdala was reduced (Derbyshire et al. 1997). Similar findings were recorded in cats (Sakiyama et al. 1998).

More recent lines of evidence are now beginning to substantiate a prominent role for the hippocampus in pain processing. Although several brain molecules modulate nociception, including prostaglandins, several neuropeptides, interleukins, tumour necrosis factor, angiotensin, bombesin and CCK, attention has focused on an endogenous peptide, orphanin FQ (Reinscheid et al. 1995), also termed nociceptin (Meunier 1997). This peptide is reported to mediate hyperalgesia by binding to the orphan receptor, ORL1 (Shimohigashi et al. 1996, Meunier 1997). It is not known physiologically where nociceptin is produced and the nature of its principal target sites for action. The nociceptin receptor is widely distributed in the brain (Neal et al. 1999); however, this receptor is functionally coupled to G-protein coupled inwardly rectifying $\mathrm{K}^{+}$channel (GIRK) polypeptides (Ikeda et al. 1997) that are prominently expressed in the hippocampus - expression of GIRK1 is enriched in the hippocampus, olfactory bulb, thalamus and cerebellum, whereas transcripts for all GIRK (and IRK) molecules examined were particularly abundant in the dentate gyrus (Kobayashi et al. 1995, Karschin et al. 1996, Ponce et al. 1996; see in particular the in situ hybridisation study by Karschin et al. 1996, which reveals uniformly robust expression of IRKs 1, 2 and 3 and GIRKs 1, 2 and 3 in the dentate gyrus, with lesser expression in CA1-3). All are expressed in the olfactory bulb, with diffuse signal in the cortex, and IRK2 and GIRK1 and 3 being expressed strongly in cerebellum;
GIRK2 is also expressed in the cerebellum, but most strongly in the hippocampus; significant GIRK4 expression was not detected in any brain region. Notably, nociceptin treatment of hippocampal slices inhibited LTP (Yu et al. 1997), whereas infusion of nociceptin into the hippocampus disrupted spatial learning (Sandin et al. 1997). Conversely, LTP and spatial learning were facilitated in mice lacking nociceptin receptors (Manabe et al. 1998, see also Mamiya et al. 1998).

\section{Ionic sensing: calcium sensing receptor and} sodium-hydrogen exchanger The hippocampus may also register ionic parameters. The calcium-sensitive receptor, $\mathrm{CaR}$, is a member of the seven-transmembrane G-protein coupled receptor family. Comparative in situ hybridisation of $\mathrm{CaR}$ expression in brain revealed strongest staining in the subfornical organ, olfactory system, hippocampus (especially CA3), amygdala, hypothalamus and cerebellum (Rogers et al. 1995). Immunohistochemistry revealed particularly high levels and distinct laminar distribution in the hippocampus (principally CAs 1-3) and cerebellum (Ruat et al. 1995); cell bodies were not generally stained, but were surrounded by intensely stained puncta, suggesting an association with synaptic terminals (Ruat et al. 1995, Rogers et al. 1995). These authors speculated that the expression of $\mathrm{CaR}$ in the brain may mediate the major alterations in cognition associated with increases or decreases in serum $\mathrm{Ca}^{2+}$; note that synaptic potentiation in the hippocampus is critically dependent upon external $\mathrm{Ca}^{2+}$ concentrations (e.g. McGuinness et al. 1991).

The brain is also sensitive to $\mathrm{Na}^{+}$and osmolarity, but the specific receptors have not been formally identified. In addition to CaR itself, NHE4 may be a candidate. Sodium-hydrogen exchangers generally regulate cell volume and intracellular $\mathrm{pH}$. Whereas NHE1 is ubiquitously expressed in most if not all body tissues, including the hippocampus, NHE2, 3 and 4 are tissue-specific (Bookstein et al. 1994). NHE2 is, like NHE3, expressed in the stomach and intestinal epithelia, but is also found in the kidney. The remaining family member, NHE4, is qualitatively different from the other sodium-hydrogen exchanger species, despite sharing significant sequence homology. Unlike the other cloned species, NHE4 is inactive except under conditions of cell hyperosmolarity and, even then, the ion flux is very much lower than for the other exchangers and has unusual kinetics (Bookstein et al. 1996), suggesting a regulatory role. The pattern of expression of NHE4 is also decidedly unusual: aside from being expressed in the kidney medulla, NHE4 expression in brain, as assessed by in situ hybridisation, has so far been detected only in the cornu ammonis fields of the hippocampus (Bookstein et al. 1996). NHE4 interacts with the cellular cytoskeleton, and thus could potentially modulate the activity of other 
cell-surface proteins and ion channels, including mechanosensitive neurotransmitter receptors such as the $\mathrm{N}$-methyl-D-aspartate receptor that are also attached to the cell matrix (Wyszynski et al. 1997). If this is the case, NHE4 could modulate hippocampal neuronal activity as a function of osmolarity, although this has not yet been demonstrated experimentally.

There are also hints that the hippocampus might be involved in fluid exhange or salt homeostasis, or both. In addition to the sodium-hydrogen exchanger NHE4, NHE1 is well expressed in the formation (Pickard 1996), as is the mineralocorticoid receptor (see above), also responding to the salt regulator, aldosterone - all in parallel with the situation in the kidney. Renin and angiotensin are also expressed (Inagami et al. 1980, Weyhenmeyer \& Phillips 1982, Lynch et al. 1986). Although a role in salt hunger (Denton 1982) has been suggested (Murphy \& Brown 1970), fluid exchange has not been documented, but could potentially underlie facilitated ligand access to neurones in the hippocampus and other brain regions.

\section{Hypothesis: the enteroceptive hippocampus - a metabolic and endocrine sensor}

Together, the above data argue that the hippocampus and memory respond to a great diversity of physiological parameters, including blood pressure and ion balance, infection and immunity, pain, reproductive status, satiety and stress. Peripherally or locally synthesised ligands can often gain access to the hippocampus, and receptor binding can be associated with changes in neuronal excitability and induction of LTP, brain function and behaviour. Although each individual case is open to scrutiny, the combined evidence is overwhelmingly in favour of modulation of hippocampal function by hormones and metabolites. Nevertheless, the hippocampus is not unique in displaying a variety of receptors, and the hypothalamus in particular - also the neocortex, amygdala and olfactory system - can all be rich sites of expression. However, the robustness and diversity of expression in the hippocampus is unusual; this may provide a clue to the evolutionary origin and present-day function of the hippocampal formation. The following hypothesis is prompted: that the original function of the hippocampus was in sensing internal metabolic and hormonal status ('enteroception') (see Note 1 that follows). This lays open the possibility that enteroception can guide cognitive function, including aspects of memory, in the vertebrate brain.

[Note 1. 'Enteroceptive' (en-; in, inside [Greek]), (also 'interoceptive'), internal sensing; from 'exteroceptive' (ex-; out, out of [Greek]) used by Herrick (1926) to describe external sensing performed by the olfactory system.]

\section{Enteroception and the evolution of the hippocampus}

The hippocampus is richly adorned with receptors for all types of ligand; this may reflect its evolutionary origin. The converse hypothesis - that the computational task performed by the hippocampus was first neutral to internal status, and receptor expression accumulated only later - is not supported here. It is suggested here that the hippocampus evolved from and in association with a group of modules, including the olfactory system (and perhaps the amygdala), with specialised roles in sensing metabolites and hormones. Before discussing a specific link between the hippocampus and the olfactory system, two points are considered briefly: firstly, that the brain in general can sense internal metabolic and hormonal status, and secondly, that the hippocampus, in particular, is involved in such enteroception.

\section{Evidence that the brain can cognitively sense metabolic context}

Is there a brain mechanism for cognitively detecting internal metabolites and hormones? Here, cognitive sensing is distinguished from internal homeostatic sensing mediated prominently by the hypothalamus. Over and above such mechanisms, it is argued below that the brain can directly sense and respond to enteroceptive inputs although, clearly, some such circuits do not include the hippocampus.

Conditioned taste aversion Conditioned taste aversion (CTA) is discussed first because, although it may provide the best paradigm for brain sensing of soluble molecules, it is likely to be misleading regarding hippocampal function. Animals develop a profound aversion to a particular taste or smell if that stimulus has previously been paired with a metabolic stimulus, such as administration of lithium chloride, that elicits 'malaise' (reviewed by Kiefer 1985, Yamamoto 1993). Thus the brain can sense a noxious metabolic stimulus although the ligands and receptors involved have not been determined. Lesions to many brain regions, including but not restricted to the amygdala, parabrachial nucleus, hypothalamus, medial thalamus, hippocampus and gustatory cortex, all diminish CTA responses (Yamamoto \& Fujimoto 1991, Yamamoto et al. 1995), arguing that several brain regions are involved in sensing noxious metabolic stimuli or processing such information, and not just the hippocampus. Lesions to the hippocampus alone do affect CTA, but in a complex manner (Krane et al. 1976, Kimble et al. 1979, Miller et al . 1986, Reilly et al. 1993). However, from an evolutionary standpoint, CTA may be a primitive response that pre-dates the divergence and specialisation of the chemosensory regions of the brain.

Self-rewarding behaviour Many animals learn to selfadminister a variety of 'rewarding' drugs, including 
alcohol, amphetamines, cocaine, nicotine and phencyclidine, suggesting that some brain centres can respond to these blood-borne agents and transmit this information for learning purposes. Nevertheless, specific targeting of the hippocampus seems unlikely, although the receptor targets for drugs provoking self-administration are abundant in the hippocampal formation and many such drugs have been demonstrated to affect hippocampal neuronal excitability and generally inhibit LTP induction (Desmond et al. 1991, Delanoy et al. 1983, Stringer et al. 1983, Smith et al. 1993, Sawada et al. 1994, Wayner et al. 1997). Other studies have centrally implicated the adjacent nucleus accumbens, although other brain regions, including the hippocampus itself, are clearly involved (Bardo 1998). The nucleus accumbens responds to electrical stimulation of the hippocampus (MacLean 1975), emphasising close connections between these brain regions. However, in evidence for an involvement of the hippocampus in self-rewarding behaviour, behavioural dependence of rats trained in a drug discrimination paradigm for nicotine could be replaced by administration of nicotine directly into the dorsal hippocampus, but not into other brain regions tested (Shoaib \& Stolerman 1996). Notably, some animals can learn to self-administer glucocorticoids (Piazza et al. 1993) that can preferentially target the hippocampus (also the hypothalamus and amygdala).

Hippocampal stimulation Human volunteers receiving electrical stimulation of the hippocampal formation report visceral sensations, but only rarely hallucinations (reviewed by Halgren 1982). These sensations are often 'epigastric', consisting of a rising sensation from the stomach and accompanied by nausea. Such sensation is independent of the site of stimulation, and is to be contrasted with cortical stimulation, which generally produces specific recall or hallucination that varies according to site (Halgren 1982). However, that study did not discriminate between direct sensing of body parameters by the hippocampus, and indirect sensing of physiological changes induced by the stimulation procedure.

Humoral components and memory It has been suggested that blood components can comprise part of the context of memory formation and retrieval. Antigens in the bloodstream can act as specific cues for associative learning (reviewed by Ader \& Cohen 1991). Internal states such as hunger and thirst (depleted glucose or water) can be used as learning cues (Kendler 1946, Davidson 1987), and insulin (for which the brain receptor is abundant in the formation) can be used as an unconditioned stimulus for associative learning (Davidson 1987), although, in that study, signal transduction via the brain insulin receptor was not distinguished from signalling via glucose concentration changes. In rats learning a T-maze discrimination test under pentobarbitone or saline treatment, performance was optimal with the same drug status but no better than chance when the treatments were reversed (Overton 1964). In human volunteers asked to perform a learning task with or without having ingested ethanol, the accuracy of recall after 2 days was most effective when alcohol concentrations were the same as during the learning phase (Weingartner \& Faillace 1971). These studies did not examine whether the hippocampus mediated the metabolic sensing involved.

Internal sensing deficits in patient $\mathbf{H} \mathbf{M}$ Hebben et al. (1985) reported that, in addition to his profound memory impairment associated with hippocampal damage, patient $\mathrm{H} \mathrm{M}$ almost never complained regarding internal states such as hunger, thirst, pain or fatigue. When questioned, he was as likely to rate himself as hungry or thirsty immediately after a meal as just before the meal. Only one of four global amnesic patients tested at the same time had difficulty in sensing meal status, which suggests that the sensory deficit is unrelated to memory impairment, but in none of these patients was the memory deficit as pronounced as that in H M (Hebben et al. 1985). The same study revealed that patient $\mathrm{H} \mathrm{M}$ was also impaired on a thermal pain perception test, but because his lesion includes the amygdala (Corkin et al. 1997), it is plausible to suggest, as argued by Hebben et al. (1985), that some of these deficits are due to the amygdaloid lesion.

Experimental hippocampal lesions and internal sensing Rats with selective lesions affecting the hippocampus are affected in their response to food deprivation signals (Davidson \& Jarrard 1993, see also Jarrard 1993) and display a complex but marked behavioural abnormality that affects both eating and drinking (Osborne \& Dodek 1986, Osborne \& Flashman 1986), best described as 'little and often' (Clifton et al. 1998). Hippocampal lesions block sodium 'appetite' in response to formaldehyde reduction of body sodium content (Murphy \& Brown 1970); lesioned animals are also unable to match location with internal status (Hsiao \& Isaacson 1971). These studies are consistent with the suggestion that the hippocampus can provide enteroceptive information for the encoding and recall of memory as a function of context (Hirsh 1974).

Conscious versus unconscious sensing The brain can sense internal hormones and metabolites (enteroception) and can use this information for cognitive purposes (behavioural guides, formation of memory associations). Several brain regions can act as targets for enteroceptive inputs, and certainly not just the hippocampus, although the hippocampus (and amygdala) features prominently. This raises the intriguing question of whether enteroceptive inputs can be perceived by the conscious mind. In the case of exteroceptive inputs (i.e. odour and taste), brain effects can be noted in the absence of conscious sensing brain responses to odours can take place in patients who 
are asleep (Badia et al. 1990) or who deny sensing any odour signal (Sobel et al. 1999); volatile agents that target the vomeronasal organ do so without any conscious perception (Monti-Bloch et al. 1998) and important gustatory components (e.g. umami substances) have no discernible taste (Kurihara \& Kashiwayanagi 1998). Several states, including hunger, thirst, fatigue, fever, malaise, and stress, can be sensed consciously; there are anecdotal reports of self-administration of coagulation factors in patients with haemophilia before any bleeding disorder, and of diabetic patients taking remedial action before a glycaemic event. It may be, nevertheless, that many enteroceptive inputs contribute to memory and behaviour without achieving a threshold for conscious perception.

The above studies demonstrate three points: 1) the brain can sense internal metabolites and hormones; 2) this information can be incorporated into new memories and can guide behaviour; 3) several brain regions are involved in these processes, predominantly including the hippocampus, amygdala and functionally linked areas.

\section{Evolution from a primitive sensory epithelium}

It is argued that the hippocampus and related brain areas can sense the composition of the internal milieu (enteroception) in much the same way as the olfactory system can sense external substances (exteroception). It seems unlikely that the machinery for sensing soluble metabolites evolved independently; rather, the hippocampus may have evolved from a group of modules, including the olfactory system, with primary roles in sensing diffusible molecules. Riss et al. (1969) suggested that the olfactory system and hippocampus might have diverged early in evolution, and proposed that (the limbic system including the hippocampus) 'is responsive to the internal milieu, whereas the olfactory system, a derivative of the limbic system, is responsive to the external chemical milieu'. Evidence linking the hippocampus and the olfactory system is reviewed briefly below.

Anatomical evidence In the earliest vertebrates, the olfactory system and the hippocampus (with the adjacent piriform region) are no more than contiguous unspecialised anatomical areas that line the lateral ventricle of the primitive telencephalon (Fig. 3A). This is well illustrated by the careful illustrations of brain sections of the common frog (Rana pipiens) presented by Hoffman (1966) (Fig. 3B). Herrick (1926) entertained the notion of a common origin, whereas Sarnat \& Netsky (1974) suggested that the medial olfactory area of lower vertebrates is homologous to the septum, hippocampus and primordium of the neocortex, and the lateral olfactory area is homologous to the entorhinal cortex, a brain area intimately involved in presentday hippocampal function. Nieuwenhuys et al. (1997), reviewing the evolutionary anatomy of the vertebrate brain, conclude that not just the hippocampus, but also the entirety of the cerebral telencephalic hemispheres, emanates from purely olfactory centres.

Developmental evidence: functional interdependence The data from developmental analysis, particularly using retroviral markers to track the fate of the neurone in the developing forebrain (Grove et al. 1992), are ambiguous regarding the development of the cortex, hippocampus and olfactory bulb, particularly because different external influences or inductive effects could cause regionally distinct effects on an initially uniform developmental structure (see the discussion held by Walsh \& Lamantia, appended to Boncinelli et al. 1995, pp 110-116). Overlapping developmental specification is suggested by the finding that hippocampal progenitor cells can differentiate to form olfactory neurones (Suhonen et al. 1996). It has been proposed (Humphrey 1966), and confirmed (Daikoku \& Koide 1997), that hippocampal development, particularly of the dentate gyrus, is critically dependent on olfactory inputs. Efferents from the olfactory bulb reach the adult hippocampus (MacLean 1975) (in addition to the amygdala): for example, fast waves can be recorded in the dentate gyrus in response to olfactory stimuli (Heale 1994). Removal of the olfactory bulbs in rodents produces biochemical changes in the hippocampus (Tiong \& Richardson 1990) and can impair learning in a radial maze task (Hall \& Macrides 1983).

Molecular evidence Transcription factors may be particularly informative, because they contribute to the developmental specification of a tissue. Expression of the WizL (widely-interspersed zinc finger) transcript is restricted to the olfactory bulb and the dentate gyrus (Matsumoto et al. 1998), but this could reflect the presence of dividing cells therein (see below). Further evidence derives from the analysis of three other genes encoding transcription factors: Tlx (tailless), Emx-2 (a cognate of the Drosophila head gap gene empty spiracles) and Tbr-1 (T-box brain gene), and the pattern of expression of transcripts encoding the ME2 transcription factor. Mice lacking the Tlx product show a concomitant reduction in the size of the olfactory bulb and limbic structures, particularly the dentate gyrus (Monaghan et al. 1997), whereas in mice mutant at the Emx2 locus, the dentate gyrus fails to develop, CA1/3 development is impaired, and there are pronounced defects in the olfactory system (Pellegrini et al. 1996, Yoshida et al. 1997). During development, robust, restricted and contiguous Tbr-1 expression is observed from the olfactory bulb through the neocortex to the hippocampus (Bulfone et al. 1995) (Fig. 3C); an intriguingly similar pattern is generated by the ME2 transcription factor, although some cerebellar expression has also been noted (Soosar et al. 1994). In addition to these transcription factors, both the 'olfactory' G protein (Jones \& Reed 1989) and the 'olfactory' cyclic 


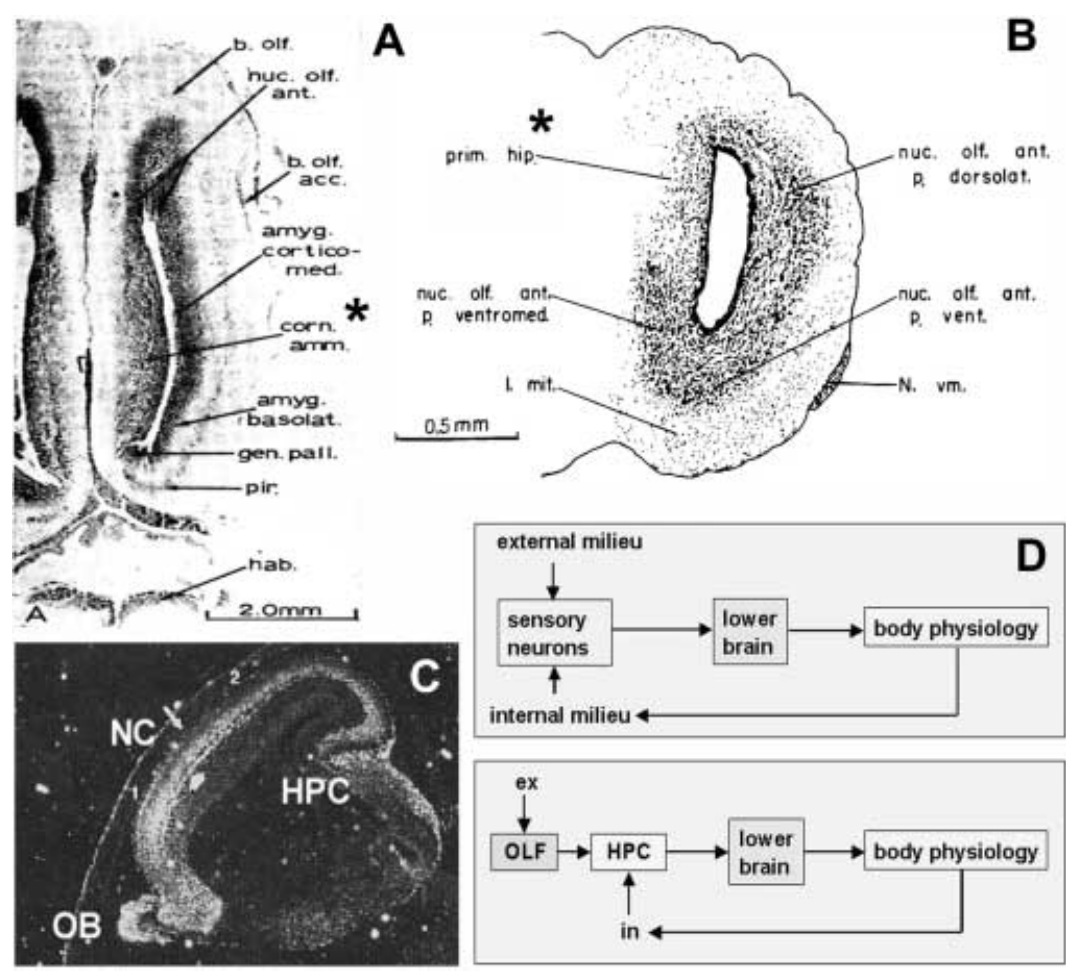

Figure 3 Evolution of the hippocampus from a sensory epithelium. (A) Section through the brain of the African lungfish, Protopterus; the primordial hippocampus ( ${ }^{*} \mathrm{corn}$. amm.) is indicated. (Reproduced from Fig. 7 in Schnitzlein (1996) (C) Georg Thième, with permission.) (B) Brain section of the common frog, Rana pipiens; the primordial hippocampal formation ( ${ }^{*}$ prim. hip.) is indicated. (Reproduced from Fig. 1 in Hoffman (1996) (C) Georg Thième, with permission.) (C) Contiguous expression of the T-box brain 1 transcription factor Tbr- 1 through olfactory bulb, neocortex and hippocampus in sections of embryonic day 16.5 mouse brain, revealed by in situ hybridisation, illustrating the contiguous development of the hippocampus (HPC), neocortex (NC), and olfactory bulb (OB). (Reproduced from Fig. 5 in Bulfone et al. (1995) (C) Cell Press, with permission.) (D) Suggested evolution of the olfactory system (OLF) and hippocampus (HPC), responsible for external and internal sensing, from a primitive sensory epithelium that sensed both internal (in) and external (ex) milieux.

nucleotide gated channel are prominently expressed in the hippocampus (Pickard 1996, Bradley et al. 1997).

Electrophysiological evidence Epileptic discharges often originate in the vicinity of the hippocampus, but focal origins can also be found in the olfactory bulb (Araki et al. 1995). The phenomenon of LTP can be demonstrated in the olfactory system (Ennis et al. 1998), although the capacity to display LTP is probably shared by all regions of the central nervous system (CNS), and perhaps by the peripheral nervous system. Both the hippocampus and the olfactory bulb display cyclic waves of synchronised neuronal activity (e.g. hippocampal $\theta$ rhythm) and there is evidence that these functionally interconnect the two regions (Kay \& Freeman 1998). Oscillatory potentials in the olfactory bulb are also synchronised with oscillations in the prepiriform cortex and lateral entorhinal area (Eeckman and Freeman 1990) - cortical regions communicating directly with the hippocampus. It may be presumed that some hippocampal oscillations are similarly synchronised - for example, $\theta$ activity in the rodent hippocampus synchronises with patterns of sniffing/olfactory exploration (Komisaruk 1970).

Cell division and cell loss One further striking argument linking the hippocampus and the olfactory system, although probably not the most robust, comes from a different line of evidence. Although most neurones are post-mitotic, in both the olfactory system and the dentate gyrus there are neurones that continue to divide in adult life (e.g. Altman \& Das 1965, Mares 1975), in distinct contrast from other brain regions, with the possible exception of the cerebellum (see Note 2 that follows). Although it is unknown why continued neuronal proliferation is required in these tissues, chemical desensitisation in the 
olfactory system could necessitate frequent cell turnover; the same could hold for the hippocampus. Although cell division is restricted to the dentate gyrus, it is tempting to speculate that cells lost in the CA1-3 regions (which are exquisitely sensitive to excitotoxic injury) could be replaced from dentate precursors - although there is little direct experimental support for this conjecture (but see Grove et al. 1992). Impaired cell division in old age may explain why hippocampal function and olfaction decline in parallel (Yousem et al. 1998), and patients with Alzheimer's disease, a condition associated with memory loss and hippocampal dysfunction, show degeneration of olfactory neurones (Talamo et al. 1989) and are impaired in olfactory identification (Thompson et al. 1998).

[Note 2. X-Irradiation of the rat neonate abolishes cell division and leads to extensive depletion of denate granule neurones (Bayer \& Altman 1975) and spatial navigation deficits (Czurko et al. 1997). Similar treatments affect the olfactory bulb (Halasz 1986; Kosaka et al. 1992). Glucocorticoids are key regulators of dentate granule cell proliferation (reviewed by Gould \& McEwen 1993); studies on the olfactory system have not been reported. In the rat, adrenalectomy causes extensive cell loss in the dentate gyrus, principally by apoptotic mechanisms; this is prevented by corticosteroid replacement (Sloviter et al. 1989, Gould et al. 1990, Armstrong et al. 1993). Loss occurs principally in young animals, but also later (Sapolsky et al. 1991) - although, curiously, a small proportion of animals with no detectable glucocorticoids showed no cell loss (Jaarsma et al. 1992). Conversely, in the adult, excess glucocorticoids may suppress cell proliferation (Gould et al. 1992) and increase neuronal death - for instance, infusion of a neurotoxic ATP antimetabolite leads to selective loss of dentate granule cells, adrenalectomy significantly reduces the damage, and neuronal loss is generally exacerbated by corticosterone (Sapolsky 1985, reviewed by Sapolsky et al. 1986, McEwen 1999).]

The simplest interpretation of these summated data, but perhaps not the only one, is that the hippocampus and olfactory system share a common and early evolutionary origin (Fig. 3D). This split could have been driven by the closing of the brain ventricles that were previously exposed to the external milieu. The exploitation of sex steroids as olfactory pheromones by some present-day fish may be a relic of the overlap between olfactory and enteroceptive signalling.

\section{Hippocampal control of body physiology}

It has been argued that the hippocampus can sense physiological parameters. This could reflect feedback control - a brain region that responds to biochemical changes in body milieux might itself regulate body physiology. In the following section, it is argued that the hippocampus not only responds to, but also governs body physiology.

Cognitive processes within the brain are known to exert a large degree of control over body physiology. Reflex-like behaviour is common - the presence of a predator elicits the secretion of stress hormones and a flight or freeze response. Before we dismiss this as a reflex, it must be recognised that the response is to the perception of the predator. This nuance is illustrated by well-documented instances in which the mere sight of a plastic rose, or a picture of a hayfield, can precipitate an asthmatic/allergic attack in the sensitive patient (Ader \& Cohen 1991). Control can be volitional, exemplified by patient $\mathrm{S}$, who could modify his heart rate (and other physiological parameters) at will (discussed in Kolb \& Whishaw 1990).

The following turns to a probable second role of the hippocampus - that of regulating body physiology. As will be seen, this dual role may have important implications for our understanding of memory processes.

\section{The hippocampus and body physiology}

A large body of evidence argues that the hippocampus is centrally involved in brain control of body physiology. For instance, epileptic seizures, often originating in the hippocampus, can have multiple effects on physiological regulation, including thermoregulation, and blood pressure, respiratory, and gastrointestinal function. Encephalitis with memory impairment has been linked to uncontrolled and reflex-like drinking that is more characteristic of hypothalamic stimulation, in addition to disordered temperature regulation (Howe et al. 1983). In such studies, a direct involvement of the hippocampus is often hard to prove, although viral infections often affect the hippocampal formation (see Note 3 that follows) and probably predispose to seizure. More direct evidence derives from electrical stimulation of the awake or anaesthetised rat hippocampus: this can evoke marked decreases in heart rate, blood pressure, and ventilation rate (Ruit \& Neafsey 1988) or modify eating and drinking behaviours (O'Keefe \& Nadel 1978). In the conscious human, electrical stimulation of the hippocampus can produce visceromotor and endocrine effects on heart rate, blood pressure, respiration and gastric secretion (reviewed by Halgren 1982), although these are not always recorded ( $\mathrm{R}$ L Isaacson, personal communication).

[Note 3. Virus infection via the olfactory/hippocampal virus pathway may mediate downstream physiological changes, including immunosuppression. Spread after nasal entry may be facilitated by direct afferents, by prominent receptor expression (including the 'prion' receptor), and by dividing neurones - selective spread to the hippocampus, cortex, amygdala, and brainstem has been reported for bornavirus, herpes simplex virus (HSV), human immunodeficiency virus (HIV), measles, mouse parovirus, rabies, 
and vesicular stomatitis virus (VSV). Virus-mediated degeneration may contribute to learning deficits (bornavirus, HSV), behavioural abnormalities/aggression (rabies, HSV) and immunosuppression (HIV, possibly rabies). Bornavirus, VSV, and lymphocytic choriomeningitis virus are associated with persistent changes in hippocampal function, despite clearance of virus; virus infection could contribute to Alzheimer's disease and epilepsy (not reviewed).]

Hippocampal control of the HPA axis, immunity, blood pressure, reproduction, and other physiological parameters

Hypothalamic-pituitary-adrenal axis Hippocampal control of the HPA axis and the production of downstream hormones, including but not restricted to adrenal glucocorticoids and catecholamines, have been amply demonstrated (Feldman 1962, Van Hartesfelt 1975, Herman et al. 1989, 1992, 1996, Jacobson \& Sapolsky 1991, Feldman et al. 1995). Generally, the hippocampus inhibits the HPA axis; lesions result in increased production of hypothalamic corticotrophin-releasing factor and in increased adrenal steroid concentrations (Herman et al. 1989, 1992). Disruption of the genes encoding the glucocorticoid or mineralocorticoid receptor produces a similar effect (Berger et al. 1996), suggesting that these receptors mediate feedback inhibition. Other work suggests that feedback inhibition operates principally via the mineralocorticoid receptor in the hippocampus, but via the glucocorticoid receptor at extrahippocampal sites (van Haarst et al. 1997). However, hippocampal regulation of glucocorticoid secretion is complex, and lesions can result in increase or decrease in glucocorticoid, or a change in the diurnal rhythm of glucocorticoid secretion, and the outcome may correlate with the type of lesion and the time delay between hippocampal lesion and measurement. Electrical stimulation of the hippocampus can also facilitate or impair glucorticoid production, depending on the procedure used. These findings suggest that hippocampal regulation of glucocorticoid production is not tonic, but is instead subject to active regulation.

Immunity Control extends to the immune system, and Porter (1953) demonstrated that electrical stimulation of the hippocampus could produce eosinopenia; stimulation of adjacent brain regions was far less effective. Hippocampal lesions affect the development, differentiation and function of cells and tissues of the immune system, with major effects on cellular and humoral immunity (Ader et al. 1991, Haas \& Shauenstein 1997). Effects are partly due to control over the production of immunosuppressive glucocorticoids, although other pathways are likely to operate (Munck et al. 1984): the hippocampus responds to several immune mediators, including ILs-1, -2 and -6 (example 4 above), and could control their production. As we saw earlier, the hippocampal and olfactory systems may be functionally interconnected; it is of interest that olfactory bulbectomy in rodents is associated with changes in immunological function as assessed by mitogenstimulated proliferation, neutrophil phagocytosis, and monocyte activity (Song \& Leonard 1995).

Blood pressure Either injection of dynorphin-A(1-8) into the hippocampal formation, or electrical stimulation at the same site, can result in a reduction in blood pressure (Ruit \& Neafsey 1988, Wang \& Ingenito 1994). AVP infused intracerebroventricularly reduced the pressor response induced by electrical stimulation of the mesencephalic reticular formation; this effect was abolished by lesions to the dorsal hippocampus (Versteeg et al. 1984). Intra-arterial injection of the $\beta$-adrenergic blocker propranolol results in a rapid depressor response. Here the drug and a metabolite thereof accumulate preferentially in the hippocampus (Garvey \& Ram 1975a) and, when the drug was injected into different brain regions, the lowest effective dose and fastest kinetics for blood pressure reduction were observed on injection into the hippocampus (Garvey \& Ram 1975b). Heart rate control during aversive conditioning is also abnormal in hippocampally lesioned animals (Caul et al. 1969).

Reproduction Hippocampal regulation of reproductive hormones ( $\mathrm{LH}$ and $\mathrm{FSH}$ ) has been demonstrated (Kawakami \& Kimura 1975), and effects on puberty have been noted. In rabbits, hippocampal stimulation can precipitate ovulation; this was not obtained in rats, although either hippocampal lesion or fornix transection can increase serum LH and FSH (reviewed by McGowan-Sass \& Timiras 1975).

Other physiological parameters In addition to regulation of stress, immunity, blood pressure, and reproduction, evidence has been provided that the hippocampus can govern other body parameters including blood coagulation (Gunn \& Hampton 1967, Ermolaev 1973) and milk ejection (Tindal \& Blake 1984), in addition to heat regulation, hepatic glucose metabolism, and production of insulin and glucagon, as demonstrated by a series of studies by Kawakami and colleagues (see Saito et al. 1989, 1990 and references therein). Notably, in some instances at least, the mechanism of control may bypass the HPA axis and take place through direct innervation of body organs probably including the ovary, liver, kidney, bone marrow, spleen and thymus (Kawakami et al. 1981, Seto et al. 1988, Ader et al. 1991) and the adrenal (Parker et al. 1993).

Temporal sensing and regulation Many hormones show circadian and circannual concentration variations: the primitive hippocampus could have used these to register temporal context. The present-day mammalian brain has more elaborate timing mechanisms, but which may also involve the hippocampus (Raitiere 1992). Animals bearing hippocampal lesions have deficits in 
performing tasks involving a time-delayed reward (Isaacson \& Schmaltz 1968) and in sequence memory (Kesner 1985), and patient H M is unable to estimate time duration (Richards 1973). Conversely, one may speculate that the hippocampus could contribute to the diurnal regulation of neuroendocrine hormones.

\section{Hippocampal lesions and cognitive control of body physiology}

The hippocampus, in addition to recording enteroceptive data, receives cortical efferents - it may thus control body physiology as a dual function of enteroceptive and cognitive inputs, and not as a simple function of physiological demands. Illustrating this regulation, hippocampal lesions reduce grooming activity and provoke exploration (dependent on ambient illumination; Jarrard 1993, R L Isaacson, personal communication); this behavioural change was abolished by adrenalectomy but then restored by corticosterone (Nyakas et al. 1983). Glucocorticoid concentrations increase during 'extinction', in which the outcome of a behaviour does not match the expected outcome (Coover et al. 1971), and also during exposure to a novel environment (e.g. Handa et al. 1994). Here, hippocampal lesions impair the glucocorticoid increase and the concentrations fail to acclimatise (Johnson \& Moberg 1980). Glucocorticoid concentrations in rats also increase markedly in response to a previously learned aversive taste (but not with a neutral taste). Crucially, in this study the increase in glucocorticoid was abolished by hippocampal lesions (Smotherman et al. 1981).

Thus hippocampal activity modulates body physiology. This is principally through neuronal outputs, but may be partly paracrine if some ligands can target the hippocampus and are themselves expressed in the formation - for example, angiotensin (Weyhenmeyer \& Phillips 1982, Lynch et al. 1986) and renin (Inagami et al. 1980). Taken together, the above observations suggest that, as part of the enteroceptive role attributed to the hippocampus, information supplied by the formation is transmitted to other brain (including the hypothalamus) and body regions to exert control over body physiology. Indeed, Alzheimer's disease (characterised by early dysfunction of the hippocampus) has been regarded as a metabolic disorder (Landin et al. 1993, Vanhanen \& Soininen 1998). However, the hippocampus is not the only brain region governing these physiological responses. The amygdala (below) is clearly a major player, while many brain regions interconnected with the hippocampus, amygdala, and hypothalamus (such as the cingulate cortex, fornix, lateral septal and medial mammillary nuclei, and locus coeruleus) can, when stimulated, all produce pronounced changes in blood pressure, ventilation rate, and so on.

\section{Behavioural inhibition and the neuroendocrine code}

A primary role of the hippocampus is in the integration of enteroceptive and cognitive stimuli, and (together with the amygdala, below) in directing appropriate neuroendocrine activation of the hypothalamus. The mechanism and specificity of how the hippocampus and other brain regions regulate the HPA axis remain a puzzle. Is the principal influence of the higher brain on the HPA axis excitatory or inhibitory? Early theorists proposed that the higher brain inhibits body activity (e.g. Pavlov 1927), but the brain/inhibition concept has been used in two contexts. In the first (termed here 'REST-type'), inhibition leads to HPA downregulation, suppression of active and responsive behaviours, and diminished arousal. Pavlov's (1927) 'internal inhibition' is of this type, and corresponds with theories of suppression of both arousal and HPA axis activity (discussed by Levine et al. 1986). An involvement of the hippocampus in mediating this type of inhibition has been proposed (Douglas \& Pribram 1966, Douglas 1967), and independently by Kimble (1968). In the second context (termed here the 'ROusE-type'), inhibition also leads to suppressed activity, but is accompanied by increased arousal, HPA upregulation, and increased readiness for further activity. Gray's (1982) behavioural inhibition would seem to be of this type and may correspond to Pavlov's (1927) 'external inhibition'. Overall, however, REST-type inhibition seems to predominate (Kimble 1968), as illustrated by the Kluever-Bucy syndrome, precipitated by removal of the temporal lobe in humans. In the study by Terzian \& Dalle Ore (1955), initial immobility after operative recovery was followed by memory loss accompanied by deviant hyperactivity, including insatiable appetite and hypersexuality. In other words, the higher brain normally inhibits these activities. Nevertheless, although many reports have demonstrated that removal of the hippocampus in particular leads to a general increase in behavioural and HPA axis activity (e.g. Herman et al. 1989, 1992), reports in the literature are mixed (not reviewed here) and most individuals with lesions restricted to the hippocampus do not demonstrate aberrant hyperactivity.

To pursue the inhibitory idea, Adey et al. (1957), working with monkeys and cats, showed that slow conduction between two electrodes implanted in the brainstem of these animals could be blocked by cortical stimulation and, although the exact positioning of the electrodes was unclear, the most persistent inhibition was produced by cortical stimulation in the immediate vicinity of the hippocampus. Feldman (1962) further reported that high-frequency (LTP-inducing?) stimulation $(100-200 \mathrm{~Hz})$ of the hippocampus (pyramidal cell layer) could result in complete abolition of hypothalamic potentials.

These and other reports (but far from all) accord with the observations by Kimble (1968) and suggest that the major output of the hippocampus is inhibitory upon behavioural activity and upon the activity of the HPA axis. A major caveat must be offered. Although particular inputs may suppress general hippocampal activity, and thereby 
enhance neuroendocrine activity, it may not be concluded rigorously that the hippocampus is inhibitory. For example, a general reduction in hippocampal activity might be accompanied by substantial increases in the activity of a specific subset of hippocampal neurones; it is possible (if not likely) that different hippocampal neurones can either inhibit or activate the lower brain. Studies on hippocampal $\vartheta$ rhythm suggest that the general activity (summated rate of neuronal firing) of the hippocampus is less important than the location of the neurones within the hippocampus (CAs 1 or 3 or the dentate gyrus) and their firing patterns.

Specificity of hormonal changes HPA axis activation on modification of hippocampal outputs raises the 'neuroendocrine code' problem. How are changes in activity within the hippocampus, and other brain regions, translated into specific hormonal responses? As conceived here, the code comprises two elements - coding mechanism and coding specificity. The former asks how excitatory inputs arriving, for example, in the hippocampus are translated into inhibitory outputs, and is not addressed here. The latter asks how a particular combination of stimuli gives rise to a specific pattern of endocrine secretions, whereas another combination prompts the secretion of a different group of hormones.

When an animal is exposed to a set of stimuli judged to be aversive - for instance a novel environment, pain, stress, or the remembered odour of a noxious context - brain changes prompt hypothalamic release of ACTH and other hormones, increasing not only corticosteroids and noradrenaline but also extra-adrenal steroids, thyroxine and growth hormone. Renin and prolactin also increase, with suppression of $\mathrm{LH}$ and testosterone on extended stress. Different sets of stimuli result in differential release of, for instance, corticosteroids and thyroxine (cortisol can be high during sleep but thyroxine low; Goichot et al. 1995). A separate set of environmental stimuli generates a different pattern of hormonal secretion: for example, sexual arousal in male rodents and humans is accompanied by increases in LH and testosterone production, but no alterations in corticosteroid concentrations (Carani et al. 1990). These studies did not examine the hippocampaldependence of the hormonal changes, but prompt the question of how the hippocampus and other brain regions elicit different patterns of hormonal secretion.

Part of the answer may lie in reciprocal mapping between the effector brain regions, including the hippocampus and the amygdala (see the following section), and their hypothalamic targets. Hormone secretion by the hypothalamus is performed by a group of nuclei that generally line the central ventricle. The different releasing hormones (or combinations thereof), LHRH $(\mathrm{GnRH})$, somatostatin, growth hormone releasing hormone, corticotrophin releasing hormone $(\mathrm{CRH}$ or CRF) and thyrotrophin-releasing hormone are produced by discrete periventricular nuclei (reviewed by Swanson 1991). There are several major inputs to these nuclei, the first relaying visceral information from the babal and glossopharyngeal nerves, a second from the subfornical organ, but a significant input derives from the hippocampus as well as the amygdala and cortex (Swanson 1991). Risold \& Swanson (1996) showed, by retrograde tracing, that different fields of the hippcampus irrigate different areas of the lateral septal nucleus (LSN), a major output of the hippocampus. Previous studies by Swanson and colleagues showed that hypothalamic nuclei project back to distinct although partly overlapping regions of the LSN, suggesting that output neurones of the hippocampus CA1 and CA3 fields project topographically ('map' onto) hypothalamic systems co-ordinating endocrine responses (Risold \& Swanson 1996). There is evidence that different neuroanatomical regions of the hippocampus, particularly along the dorsoventral axis, may be functionally specialised in terms of their connectivity to other brain regions (Moser \& Moser 1998) and this may extend to the hypothalamus. Because stimulation of the hypothalamus produces short-latency hippocampal potentials in the hippocampus (Feldman 1962), mapping may be reciprocal.

\section{The amygdala}

Of the brain regions modulating neuroendocrine activity, the amygdala is one of the most prominent (Van de Kar \& Blair 1999). It is argued here that the amygdala and the hippocampus are similar in that they both translate cognitive inputs into neuroendocrine activity, but do so in different ways. In evolutionary terms, both brain regions appear to have a similar antiquity. Amygdaloid stimulation produces neuroendocrine changes, as does stimulation of the hippocampus.. Lesions to the amygdala can produce major changes in expressed emotionality, including fear and aggression, although the phenotypic expression of the lesion is variable, depending on the species examined. Importantly, lesions to the amygdala act synergistically with hippocampal lesions to produce emotional disturbances (Zola-Morgan et al. 1991) and memory impairments (Mishkin 1978, Squire \& Zola-Morgan 1991). This is of note because the lesion in patient $\mathrm{H}$ M includes much of the amygdaloid complex (Corkin et al. 1997). As in the hippocampus, LTP is readily demonstrated in the amygdala (Racine et al. 1983, Chapman et al. 1990), although the phenomenon of LTP is probably common to all CNS regions. Gustatory and olfactory 'place cells' are present in the amygdala (Karadi et al. 1998) and amygdaloid stimulation tends to inhibit the activity of the HPA axis (Feldman 1962, Oomura et al. 1970). Many of the genes that are expressed in the hippocampus, hypothalamus, and olfactory system are also expressed in the amygdala (although the fact that genes also expressed in two tissues does not imply that the genes fulfil common roles at these sites). An important interaction with the 
olfactory system has been discussed (Swanson \& Petrovich 1998), and some mutations that affect the development of the hippocampus and olfactory system also impair that of the amygdala (e.g. Monaghan et al. 1997).

At this point the similarity ends. Whereas the hippocampus appears to be a uniformly continuous organ, with a single evolutionary origin, the amygdala comprises a conglomerate of different nuclei of independent origin the term 'amygdala' may incorrectly refer to an association of cell types of different functions (discussed by Swanson \& Petrovich 1998). This could, plausibly, reflect (in part) mapping of nuclei within the amygdala onto other brain nuclei, including those of the hypothalamus. In the study by Feldman (1962) it was reported that, when stimulation of the hippocampus failed to inhibit hypothalamic activity, this could be obtained by stimulating the amygdala, suggesting that the hippocampus and the amygdala map somewhat differently than the hypothalamus. This would suggest that the amygdala and the hippocampus operate in parallel, although close co-operation is suggested by the existence of prominent reciprocal communications between the hippocampus and amygdala (see Ten Donkelaar, ch $22 \cdot 11 \cdot 5$, in Nieuwenhuys et al. 1997).

Although so far unproven, it is possible that the hippocampus might determine acquired (memory/output) responses, whereas the fixed relays of the amygdala might mediate innate (genetically determined) responses. HPA activation in response to predator odour (innate) may be independent of the hippocampus (Perrot-Sinal \& Petersen 1997), whereas HPA activation as a result of a learned aversive taste (acquired) is abolished by hippocampal lesion (Smotherman et al. 1981). If so, this would imply that the deficits in sensing internal status displayed by patient $\mathrm{H} \mathrm{M}$ are due to amygdaloid dysfunction, although, clearly, the hippocampus and the amygdala intercommunicate in complex ways.

\section{Implications}

It has been argued that the hippocampus and related brain regions evolved from a simple sensory epithelium. Only later in evolution did this generate the olfactory system, responding to external chemical signals (exteroception) and the hippocampus (together with related brain regions, including the amygdala) that can sense internal metabolic status (enteroception). Chemical and hormonal sensing is a counterpart to hippocampal modulation of physiology lesions to or stimulation of the hippocampus can produce diverse neuroendocrine changes; it seems likely that the hippocampus mediates cognitive control of body physiology. The blood pressure increase that accompanies the perception of a predator amply illustrates such cognitive control, although the precise contribution of the hippocampus to this paradigm remains unclear.

This prompts the question of whether physiological control mediated by the hippocampus might contribute to its role in memory. Increased adrenal output (glucocorticoids, adrenalines), blood pressure and blood glucose (oxygen and energy supply) can facilitate memory encoding in the cortex; could the requirement for the hippocampus in memory processes be explained, in part, through the downstream physiological changes it produces? If the hippocampus contributes to temporal regulation of HPA axis activity (e.g. circadian rhythm) as suggested, it might also regulate non-specific arousal processes that themselves govern memory formation. As will be discussed in more depth elsewhere ( $\mathrm{R}$ Lathe, upublished observations), an evolutionarily old and conserved mechanism for selective memory encoding might take advantage of the hormonal hike that new and significant events produce.

Concerning LTP, synaptic potentiation would seem to facilitate hippocampal throughput and thereby HPA axis inhibition; impairment of LTP might be expected to increase HPA axis activity. Seen in this light, there is an intriguing and suggestive correlation between the nature of the ligand and the effect on LTP, which might be a relic of the early evolution of the hippocampus. Some ligands with 'negative' associations, such as glucocorticoids (stress), interleukins (infection), angiotensins (blood pressure decrease), and nociceptin (pain), seem to inhibit LTP, whereas ligands with 'positive' associations, such as aFGF (glucose and satiety), and oestrogen (fertility), enhance potentiation. This correlation, so far unproven, may provide an insight into the evolution of hormonal targeting of the brain. If 'good' ligands improve LTP and 'bad' ligands impair potentiation, LTP might provide a device for integrating diverse enteroceptive inputs. This interpretation may have significant implications for medical conditions such as anxiety (Gray 1982, Gray \& McNaughton 1996).

Finally, it is notable, although perhaps entirely fortuitous, that two hormone/receptor systems targeting the hippocampus have been highlighted by the genetic study of human cognition. The only marker so far identified that associates with high cognitive ability in children was linked to the IGF-II receptor gene (Chorney et al. 1998); a new member of the IL-1 receptor family highly expressed in hippocampus has recently been implicated in X-linked mental retardation (Carrie et al. 1999).

\section{Acknowledgements}

R L Isaacson, S G Hillier, and E deGruyse are thanked for valuable insights and encouragement, and $\mathrm{R}$ de Kloet, $\mathrm{N}$ McNaughton, Y Koteletsev, K Rose, L Amet, J O Bishop, B Davies, H Marston, J R Seckl, J J Mullins, S Grant, J Russell, and E Wood for helpful suggestions. Y Koteletsev and $\mathrm{R}$ Pinkerton are thanked for help with translations, and the Darwin library staff for their assistance. This work was supported by grants from the Gatsby Charitable 
Foundation, the Medical Research Council, the European Commission, the Biotechnology and Biological Sciences Research Council, the Ministry of Agriculture, Fisheries and Foods, and the Wellcome Trust.

\section{References}

Ader R \& Cohen N 1991 Conditioning of the immune response. Netherlands Journal of Medicine 39 263-273.

Ader R, Felten DL \& Cohen N 1991 Psychoneuroimmunology, edn 2. San Diego: Academic Press.

Adey WR, Segundo JP \& Livingston RB 1957 Corticifugal influences on intrinsic brainstem conduction in rat and monkey. Journal of Neurophysiology 20 1-16.

Ahima RS, Prabakaran D, Mantzoros C, Qu D, Lowell B, MaratosFlier E \& Flier JS 1996 Role of leptin in the neuroendocrine response to fasting. Nature 382 250-252.

Altman J \& Das GDD 1965 Post-natal origin of microneurones in the rat brain. Nature 207 953-956.

Amaral DG 1987 Memory: anatomical organization of candidate brain regions. In Handbook of Physiology, V: the Nervous System, pp 211-294. Eds JM Brookhart \& VB Montcastle. Bethesda MD: American Physiological Society.

Amaral DG \& Witter MP 1989 The three-dimensional organization of the hippocampal formation: a review of anatomical data. Neuroscience 31 571-591.

Angevine JB Jr 1965 Time of neuron origin in the hippocampal region. Experimental Neurology Suppl 2 1-70.

Araki T, Kato M \& Kobayashi T 1995 Limbic seizures originating in the olfactory bulb: an electro-behavioral and glucose metabolism study. Brain Research 693 207-216.

Armstrong JN, McIntyre DC, Neubort S \& Sloviter RS 1993 Learning and memory after adrenalectomy-induced hippocampal dentate granule cell degeneration in the rat. Hippocampus $\mathbf{3}$ 359-371.

Aronsson M, Fuxe K, Dong Y, Agnati LF, Okret S \& Gustafsson JA 1988 Localization of glucocorticoid receptor mRNA in the male rat brain by in situ hybridization. PNAS 85 9331-9335.

Badia P, Wesensten N, Lammers W, Culpepper J \& Harsh J 1990 Responsiveness to olfactory stimuli presented in sleep. Physiology and Behavior 48 87-90.

Baldwin BA, Parrott RF \& Ebenezer IS 1998 Food for thought: a critique on the hypothesis that endogenous cholecystokinin acts as a physiological satiety factor. Progress in Neurobiology 55 477-507.

Ban EMH 1994 Interleukin-1 receptors in the brain: characterization by quantitative in situ autoradiography. Immunomethods 5 31-40.

Banks WA \& Kastin AJ 1991 Blood to brain transport of interleukin links the immune and central nervous systems. Life Sciences $\mathbf{4 8}$ PL117-PL121.

Banks WA, Ortiz L, Plotkin SR \& Kastin AJ 1991 Human interleukin (IL) 1 alpha, murine IL-1 alpha and murine IL-1 beta are transported from blood to brain in the mouse by a shared saturable mechanism. Journal of Pharmacology and Experimental Therapeutics 259 988-996.

Banks WA, Kastin AJ \& Gutierrez EG 1994 Penetration of interleukin-6 across the murine blood-brain barrier. Neuroscience Letters 179 53-56.

Banks WA, Kastin AJ \& Broadwell RD 1995 Passage of cytokines across the blood-brain barrier. Neuroimmunomodulation 2 241-248.

Bantle JA \& Hahn WE 1976 Complexity and characterization of polyadenylated RNA in the mouse brain. Cell 8 139-150.

Bardo MT 1998 Neuropharmacological mechanisms of drug reward: beyond dopamine in the nucleus accumbens. Critical Reviews in Neurobiology 12 37-67.
Baskin DG, Schwartz MW, Sipols AJ, D'Alessio DA, Goldstein BJ \& White MF 1994 Insulin receptor substrate-1 (IRS-1) expression in rat brain. Endocrinology 134 1952-1955.

Bayer SA \& Altman J 1975 The effects of X-irradiation on the postnatally-forming granule cell populations in the olfactory bulb, hippocampus, and cerebellum of the rat. Experimental Neurology 48 167-174.

Bellinger FP, Madamba S \& Siggins GR 1993 Interleukin 1 beta inhibits synaptic strength and long-term potentiation in the rat CA1 hippocampus. Brain Research 628 227-234.

Berger S, Cole TJ, Schmid W \& Schutz G 1996 Analysis of glucocorticoid and mineralocorticoid signalling by gene targeting. Endocrine Research 22 641-652.

Biessels G, Kamal A, Urban IJA, Spruijt BM, Erkelens DW \& Gispen WH 1998 Water maze learning and hippocampal synaptic plasticity in streptozotocin-diabetic rats: effects of insulin treatment. Brain Research 800 125-135.

Bingaman EW, Baeckman LM, Yracheta JM, Handa RJ \& Gray TS 1994 Localization of androgen receptor within peptidergic neurons of the rat forebrain. Brain Research Bulletin 35 379-382.

Bliss TV \& Gardner-Medwin AR 1973 Long-lasting potentiation of synaptic transmission in the dentate area of the unanaesthetized rabbit following stimulation of the perforant path. Journal of Physiology 232 357-374.

Bliss TV \& Lømo T 1973 Long-lasting potentiation of synaptic transmission in the dentate area of the anaesthetized rabbit following stimulation of the perforant path. Journal of Physiology 232 331-356.

Bliss TV \& Collingridge GL 1993 A synaptic model of memory: long-term potentiation in the hippocampus. Nature 361 31-39.

Boncinelli E, Gulisano M, Spada F \& Broccoli V 1995 Emx and Otx gene expression in the developing mouse brain. Ciba Foundation Symposium 193 100-109, discussion 110-116.

Bondy C, Werner H, Roberts CT Jr \& LeRoith D 1992 Cellular pattern of type-I insulin-like growth factor receptor gene expression during maturation of the rat brain: comparison with insulin-like growth factors I and II. Neuroscience 46 909-923.

Bookstein C, Depaoli AM, Xie Y, Niu P, Musch MW, Rao MC \& Chang EB $1994 \mathrm{Na}+/ \mathrm{H}+$ exchangers, NHE-1 and NHE-3, of rat intestine. Journal of Clinical Investigation 93 106-113.

Bookstein C, Musch MW, Depaoli A, Xie Y, Rabenau K, Villereal M, Rao MC \& Chang EB 1996 Characterization of the rat $\mathrm{Na}+/ \mathrm{H}+$ exchanger isoform NHE4 and localization in rat hippocampus. American Journal of Physiology 271 C1629-C1638.

Bradley J, Zhang Y, Bakin R, Lester HA, Ronnett GV \& Zinn K 1997 Functional expression of the heteromeric 'olfactory' cyclic nucleotide-gated channel in the hippocampus: a potential effector of synaptic plasticity in brain neurons. Journal of Neuroscience $\mathbf{1 7}$ 1993-2005.

Bulfone A, Smiga SM, Shimamura K, Peterson A, Puelles L \& Rubenstein JLR 1995 T-Brain 1: a homolog of brachyury whose expression defines molecularly distinct domains within the cerebral cortex. Neuron 15 63-78.

Bunnemann B, Fuxe K, Metzger R, Mullins J, Jackson TR, Hanley MR \& Ganten D 1990 Autoradiographic localization of mas proto-oncogene mRNA in adult rat brain using in situ hybridization. Neuroscience Letters 114 147-153.

Carani C, Bancroft J, Del Rio G, Granata AR, Facchinetti F \& Marrama P 1990 The endocrine effects of visual erotic stimuli in normal men. Psychoneuroendocrinology 15 207-216.

Carlesimo GA \& Oscar-Berman M 1992 Memory deficits in Alzheimer's patients: a comprehensive review. Neuropsychology Review 3 119-169.

Carrie A, Jun L, Bienvenu T, Vinet MC, McDonell N, Couvert P, Zemni R, Cardona A, Van Buggenhout G, Frints S et al. 1999 A new member of the IL-1 receptor family highly expressed in hippocampus and involved in X-linked mental retardation. Nature Genetics 23 25-31. 
Caul WF, Jarrard LE, Miller RE \& Korn JH 1969 Effects of hippocampal lesions on heart rate in aversive classical conditioning. Physiology and Behavior 4 917-922.

Chapman PF, Kairiss EW, Keenan CL \& Brown TH 1990 Long-term synaptic potentiation in the amygdala. Synapse 6 271-278.

Chen C \& Tonegawa S 1997 Molecular genetic analysis of synaptic plasticity, activity-dependent neural development, learning, and memory in the mammalian brain. Annual Review of Neuroscience 20 157-184.

Choate JVA, Slayden OD \& Resko JA 1998 Immunocytochemical localization of androgen receptors in brains of developing and adult male rhesus monkeys. Endocrine 8 51-60.

Chorney MJ, Chorney K, Seese N, Owen MJ, Daniels J, McGuffin P, Thompson LA, Detterman DK, Benbow C, Lubinski D et al. 1998 A quantitative trait locus associated with cognitive ability in children. Pyschological Science 9 159-166.

Clifton PG, Vickers SP \& Somerville EM 1998 Little and often: ingestive behaviour patterns following hippocampal lesions in rats. Behavioral Neuroscience 112 502-511.

Cohen NJ \& Eichenbaum H 1991 The theory that wouldn't die: a critical look at the spatial mapping theory of hippocampal function. Hippocampus 1 265-268.

Cohen NJ \& Eichenbaum H 1993 Memory, Amnesia and the Hippocampal System. Cambridge, Massachusetts: MIT.

Coover GD, Goldman L \& Levine S 1971 Plasma corticosterone increases produced by extinction of operant behaviour in rats. Physiology and Behavior 6 261-263.

Cordoba Montoya DA \& Carrer HF 1997 Estrogen facilitates induction of long term potentiation in the hippocampus of awake rats. Brain Research 778 430-438.

Corfield DR, Fink GR, Ramsay SC, Murphy K, Harty HR, Watson JDG, Adams L, Frackowiak RSJ \& Guz A 1995 Evidence for limbic system activation during $\mathrm{CO}_{2}$ stimulated breathing in man. Journal of Physiology 488 77-84.

Corkin S, Amaral DG, Gonzalez RG, Johnson KA \& Hyman BT 1997 H. M.'s medial temporal lobe lesion: findings from magnetic resonance imaging. Journal of Neuroscience 17 3964-3979.

Couce ME, Weatherington AJ \& McGinty JF 1992 Expression of insulin-like growth factor-II (IGF-II) and IGF-II/mannose-6phosphate receptor in the rat hippocampus: an in situ hybridization and immunocytochemical study. Endocrinology 131 1636-1643.

Cunningham AJ, Murray CA, O’Neill LA, Lynch MA \& O'Connor JJ 1996 Interleukin-1 beta (IL-1 beta) and tumour necrosis factor (TNF) inhibit long-term potentiation in the rat dentate gyrus in vitro. Neuroscience Letters 203 17-20.

Cunningham ET Jr, Wada E, Carter DB, Tracey DE, Battey JF \& De Souza EB 1991 Localization of interleukin-1 receptor messenger RNA in murine hippocampus. Endocrinology 128 2666-2668.

Czurko A, Czeh B, Seress L, Nadel L \& Bures J 1997 Severe spatial navigation deficit in the Morris water maze after single high dose of neonatal x-ray irradiation in the rat. PNAS 94 2766-2771.

Dahl D \& Li J 1994 Long-lasting potentiation and depression by novel isoproterenol and cholecystokinin 8-S interactions in the dentate gyrus. Experimental Brain Research 100 155-159.

Daikoku S \& Koide I 1997 Destruction of olfactory inputs affects the morphogenesis of the telencephalon in rats. Archives of Histology and Cytology 60 329-345.

Dana RC \& Martinez JL Jr 1984 Effect of adrenalectomy on the circadian rhythm of LTP. Brain Research 308 392-395.

Davidson TL 1987 Learning about deprivation intensity stimuli. Behavioral Neuroscience 101 198-208.

Davidson TL \& Jarrard LE 1993 A role for hippocampus in the utilization of hunger signals. Behavioral and Neural Biology 59 167-171.

Delanoy RL, Tucci DL \& Gold PE 1983 Amphetamine effects on long term potentiation in dentate granule cells. Pharmacology, Biochemistry and Behavior 18 137-139.
Denny JB, Polan-Curtain J, Wayner MJ \& Armstrong DL 1991 Angiotensin II blocks hippocampal long-term potentiation. Brain Research 567 321-324.

Denton D 1982 The Hunger for Salt. Berlin: Springer.

Derbyshire SW, Jones AK, Gyulai F, Clark S, Townsend D \& Firestone LL 1997 Pain processing during three levels of noxious stimulation produces differential patterns of central activity. Pain $\mathbf{7 3}$ 431-445.

Desmond NL, Colbert CM, Zhang DX \& Levy WB 1991 NMDA receptor antagonists block the induction of long-term depression in the hippocampal dentate gyrus of the anesthetized rat. Brain Research 552 93-98.

Diamond DM, Bennett MC, Fleshner M \& Rose GM 1992 Inverted-U relationship between the level of peripheral corticosterone and the magnitude of hippocampal primed burst potentiation. Hippocampus 2 421-430.

Doré S, Kar S, Rowe W \& Quirion R 1997 Distribution and levels of $\left[{ }^{125} \mathrm{I}\right] \mathrm{IGF}-\mathrm{I},\left[{ }^{125} \mathrm{I}\right] \mathrm{IGF}-\mathrm{II}$ and $\left[{ }^{125} \mathrm{I}\right]$ insulin receptor binding sites in the hippocampus of aged memory-unimpaired and -impaired rats. Neuroscience 80 1033-1040.

Douglas RJ 1967 The hippocampus and behavior. Psychological Bulletin 67 416-442.

Douglas RJ \& Pribram KH 1966 Learning and limbic lesions. Neuropsychologia 4 197-220.

Dubrovsky BO, Liquornik MS, Noble P \& Gijsbers K 1987 Effects of 5 alpha-dihydrocorticosterone on evoked responses and long-term potentiation. Brain Research Bulletin 19 635-638.

Eeckman FH \& Freeman WJ 1990 Correlations between unit firing and EEG in the rat olfactory system. Brain Research 528 238-244.

Eichenbaum H, Otto T \& Cohen NJ 1992 The hippocampus - what does it do? Behavioral and Neural Biology 57 2-36.

Ennis M, Linster C, Aroniadou-Anderjaska V, Ciombor K \& Shipley MT 1998 Glutamate and synaptic plasticity at mammalian primary olfactory synapses. Annals of the New York Academy of Sciences $\mathbf{8 5 5}$ 457-465.

Ermolaev YA 1973 Effect of hippocampus stimulation on blood coagulation [in Russian]. Fiziologicheskii Zhurnal SSSR $\mathbf{5 9}$ $1393-1396$.

Feldman S 1962 Neurophysiological mechanisms modifying afferent hypothalamo-hippocampal conduction. Experimental Neurology $\mathbf{5}$ 269-291.

Feldman S, Conforti N \& Weidenfeld J 1995 Limbic pathways and hypothalamic neurotransmitters mediating adrenocortical responses to neural stimuli. Neuroscience and Biobehavioral Reviews 19 235-240.

Filipini D, Gijsbers K, Birmingham MK, Kraulis I \& Dubrovsky B 1991 Modulation by adrenal steroids of limbic function. Journal of Steroid Biochemistry and Molecular Biology 39 245-252.

Friedman JM \& Halaas JL 1998 Leptin and the regulation of body weight in mammals. Nature 395 763-770.

Gallo RV, Johnson JH, Kalra SP, Whitmoyer DI \& Sawyer CH 1972 Effects of luteinizing hormone on multiple-unit activity in the rat hippocampus. Neuroendocrinology 9 149-157.

Garvey HL \& Ram N 1975a Comparative antihypertensive effects and tissue distribution of beta adrenergic blocking drugs. Journal of Pharmacology and Experimental Therapeutics 194 220-229.

Garvey HL \& Ram N $1975 b$ Centrally induced hypotensive effects of beta-adrenergic blocking drugs. European Journal of Pharmacology 33 283-294.

Goichot B, Buguet A, Bogui P, Montmayeur A, Bourdon L, Dumas M \& Brandenberger G 1995 Twenty-four-hour profiles and sleep-related variations of cortisol, thyrotropin and plasma renin activity in healthy African melanoids. European Journal of Applied Physiology 70 220-225.

Gol A \& Faibisch GM 1966 Hippocampectomy for relief of intractable pain. Texas Medicine 62 76-79.

Gold PE, Vogt J \& Hall JL 1986 Glucose effects on memory: behavioral and pharmacological characteristics. Behavioral and Neural Biology 46 145-155. 
Gould E \& McEwen BS 1993 Neuronal birth and death. Current Opinion in Neurobiology 3 676-682.

Gould E, Woolley CS \& McEwen BS 1990 Short-term glucocorticoid manipulations affect neuronal morphology and survival in the adult dentate gyrus. Neuroscience 37 367-375.

Gould E, Cameron HA, Daniels DC, Woolley CS \& McEwen BS 1992 Adrenal hormones suppress cell division in the adult rat dentate gyrus. Journal of Neuroscience 12 3642-3650.

Gray JA 1982 The Neuropsychology of Anxiety: an Enquiry into the Functions of the Septo-Hippocampal System. Oxford: Oxford University Press.

Gray JA \& McNaughton N 1996 The neuropsychology of anxiety: reprise. In Perspectives on Anxiety, Panic and Fear. Nebraska Symposium on Motivation, vol 43, pp 61-134. Lincoln and London: University of Nebraska Press.

Grove EA, Kirkwood TBL \& Price J 1992 Neuronal precursor cells in the rat hippocampal formation contribute to more than one cytoarchitectonic area. Neuron 8 217-229.

Gunn CG \& Hampton JW 1967 CNS influences on plasma levels of factor VIII activity. American Journal of Physiology 212 124-130.

van Haarst AD, Oitzl MS \& de Kloet ER 1997 Facilitation of feedback inhibition through blockade of glucocorticoid receptors in the hippocampus. Neurochemical Research 22 1323-1328.

Haas HS \& Schauenstein K 1997 Neuroimmunomodulation via limbic structures - the neuroanatomy of psychoimmunology. Progress in Neurobiology 51 195-222.

Hahn WE \& Laird CD 1971 Transcription of nonrepeated DNA in mouse brain. Science 173 158-161.

Hakansson ML, Brown H, Ghilardi N, Skoda RC \& Meister B 1998 Leptin receptor immunoreactivity in chemically defined target neurons of the hypothalamus. Journal of Neuroscience 18 559-572.

Halasz N 1986 Early X-irradiation of rats. 1. Methodological description and morphological observations on the olfactory bulb Journal of Neuroscience Methods 18 255-268.

Halgren E 1982 Mental phenomena induced by stimulation in the limbic system. Human Neurobiology 1 251-260.

Hall JL \& Gold PE 1986 The effects of training, epinephrine, and glucose injections on plasma glucose levels in rats. Behavioral and Neural Biology 46 156-167.

Hall RD \& Macrides F 1983 Olfactory bulbectomy impairs the rat's radial-maze behavior. Physiology and Behavior 30 797-803.

Hanai K, Oomura Y, Kai Y, Nishikawa K, Shimizu N, Morita H \& Plata-Salaman CR 1989 Central action of acidic fibroblast growth factor in feeding regulation. American Journal of Physiology $\mathbf{2 5 6}$ R217-R223.

Handa RJ, Nunley KM, Lorens SA, Louie JP, McGivern RF \& Bollnow MR 1994 Androgen regulation of adrenocorticotropin and corticosterone secretion in the male rat following novelty and foot shock stressors. Physiology and Behavior 55 117-124.

Hanisch UK \& Quirion R 1995 Interleukin-2 as a neuroregulatory cytokine. Brain Research. Brain Research Reviews 21 246-284.

Harding JW, Cook VI, Miller-Wing AV, Hanesworth JM, Sardinia MF, Hall KL, Stobb JW, Swanson GN, Coleman JKM, Wright JW et al. 1992 Identification of an $\mathrm{AII}(3-8)$ (AIV) binding site in guinea pig hippocampus. Brain Research 583 340-343.

Harper RM, Gozal D, Bandler R, Spriggs D, Lee J \& Alger J 1998 Regional brain activation in humans during respiratory and blood pressure challenges. Clinical and Experimental Pharmacology and Physiology 25 483-486.

Heale VR, Vanderwolf CH \& Kavaliers M 1994 Components of weasel and fox odors elicit fast wave bursts in the dentate gyrus of rats. Behavioural Brain Research 63 159-165.

Hebb D 1949 The Organization of Behavior. New York: John Wiley.

Hebben N, Corkin S, Eichenbaum H \& Shedlack K 1985 Diminished ability to interpret and report internal states after bilateral medial temporal resection: case H.M. Behavioral Neuroscience 99 1031-1039.
Herbert J 1986 Partitioning of neuroendocrine steroids and peptides between vascular and cerebral compartments. In Psychoendocrinology, pp 9-40. Eds FR Brush \& S Levine. New York: Academic Press.

Herman JP, Schafer MKH, Young EA, Thompson R, Douglass J, Akil H \& Watson SJ 1989 Evidence for hippocampal regulation of neuroendocrine neurons of the hypothalamo-pituitaryadrenocortical axis. Journal of Neuroscience 9 3072-3082.

Herman JP, Cullinan WE, Young EA, Akil H \& Watson SJ 1992 Selective forebrain fiber tract lesions implicate ventral hippocampal structures in tonic regulation of paraventricular nucleus corticotropinreleasing hormone $(\mathrm{CRH})$ and arginine vasopressin (AVP) $\mathrm{mRNa}$ expression. Brain Research 592 228-238.

Herman JP, Prewitt CM \& Cullinan WE 1996 Neuronal circuit regulation of the hypothalamo-pituitary-adrenocortical stress axis. Critical Reviews in Neurobiology 10 371-394.

Herrick CJ 1926 Brains of Rats and Men. New York: Hafner.

Hershey T, Craft S, Bhargava N \& White NH 1997 Memory and insulin dependent diabetes mellitus (IDDM): effects of childhood onset and severe hypoglycemia. Journal of the International Neuropsychology Society 3 509-520.

Hill JM, Lesniak MA, Kiess W \& Nissley SP 1988 Radioimmunohistochemical localization of type II IGF receptors in rat brain. Peptides 9 S181-S187.

Hirsh R 1974 The hippocampus and contextual retrieval of information from memory: a theory. Behavioral Biology 12 421-444.

Hoffman HH 1966 The hippocampal and septal formations in anurans. In Evolution of the Forebrain: Phylogenesis and Ontogenesis of the Forebrain, pp 61-72. Eds R Hassler \& H Stephan. Stuttgart: Georg Thième.

Howe JG, Penney MD, Currie S \& Morgan D 1983 Thirst, resetting of the osmostat, and water intoxication following encephalitis. Annals of Neurology 13 201-204.

Hsiao S \& Isaacson RL 1971 Learning of food and water positions by hippocampus damaged rats. Physiology and Behavior 6 81-83.

Huang XF, Koutcherov I, Lin S, Wang HQ \& Storlien L 1996 Localization of leptin receptor mRNA expression in mouse brain. Neuroreport 7 2635-2638.

Huang XF, Lin S \& Zhang R 1997 Upregulation of leptin receptor mRNA expression in obese mouse brain. Neuroreport 8 1035-1038.

Humphrey T 1966 Correlations between the development of the hippocampal formation and the differentiation of the olfactory bulbs. Alabama Journal of Medical Science 3 235-269.

Ikeda K, Kobayashi K, Kobayashi T, Ichikawa T, Kumanishi T, Kishida H, Yano R \& Manabe T 1997 Functional coupling of the nociceptin/orphanin FQ receptor with the G-protein-activated $\mathrm{K}+$ (GIRK) channel. Brain Research. Molecular Brain Research $\mathbf{4 5}$ 117-126.

Inagami T, Clemens DL, Celio MR, Brown A, Sandru L, Herschkowitz N, Hoffman LH \& Kasselberg AG 1980 Immunohistochemical localization of renin in mouse brain. Neuroscience Letters 18 91-98.

Inui A, Okita M, Inoue T, Sakatani N, Oya M, Morioka H, Oimomi M \& Baba S 1989 Effect of cholecystokinin octapeptide analogues on food intake in the dog. American Journal of Physiology 257 R946-R951.

Isaacson RL \& Schmaltz LW 1968 Failure to find savings from spaced, two-stage destruction of hippocampus. Communications in Behavioral Biology 1 353-359.

Iwasaki Y, Aoki Y, Katahira M, Oiso Y \& Saito H 1997 Nongenomic mechanisms of glucocorticoid inhibition of adrenocorticotropin secretion: possible involvement of GTP-binding protein. Biochemical and Biophysical Research Communications 235 295-299.

Jaarsma D, Postema F \& Korf J 1992 Time course and distribution of neuronal degeneration in the dentate gyrus of rat after adrenalectomy: a silver impregnation study. Hippocampus 2 143-150. 
Jacobson L \& Sapolsky R 1991 The role of the hippocampus in feedback regulation of the hypothalamic-pituitary-adrenocortical axis. Endocrine Reviews 12 118-134.

Jaffe D \& Johnston D 1990 Induction of long-term potentiation at hippocampal mossy-fiber synapses follows a Hebbian rule. Journal of Neurophysiology 64 948-960.

Jarrard LE 1993 On the role of the hippocampus in learning and memory in the rat. Behavioral and Neural Biology 60 9-26.

Jarrard LE 1995 What does the hippocampus really do? Behavioural Brain Research 71 1-10.

Ji IH \& Ji TH 1991 Human choriogonadotropin binds to a lutropin receptor with essentially no $\mathrm{N}$-terminal extension and stimulates cAMP synthesis. Journal of Biological Chemistry 266 13076-13079.

Joels M 1997 Steroid hormones and excitability in the mammalian brain. Frontiers in Neuroendocrinology 18 2-48.

Joels M \& de Kloet ER 1989 Effects of glucocorticoids and norepinephrine on the excitability in the hippocampus. Science $\mathbf{2 4 5}$ 1502-1505.

Johnson LL \& Moberg GP 1980 Adrenocortical response to novelty stress in rats with dentate gyrus lesions. Neuroendocrinology 30 187-192.

Jöhren O \& Saavedra JM 1996 Expression of AT1A and AT1B angiotensin II receptor messenger RNA in forebrain of 2-wk-old rats. American Journal of Physiology 271 E104-E112.

Jones DT \& Reed RR 1989 Golf: an olfactory neuron-specific G protein involved in odorant signal transduction. Science 24 790-795.

Kamal A, Spoelstra K, Biessels GJ, Urban IJ \& Gispen WH 1999 Effects of changes in glucose concentration on synaptic plasticity in hippocampal slices. Brain Research 824 238-242.

Kar S, Chabot JG \& Quirion R 1993 Quantitative autoradiographic localization of $\left[{ }^{125} \mathrm{I}\right]$ insulin-like growth factor I, $\left[{ }^{125} \mathrm{I}\right]$ insulin-like growth factor II, and $\left[{ }^{125} \mathrm{I}\right]$ insulin receptor binding sites in developing and adult rat brain. Journal of Comparative Neurology 333 375-397.

Karadi Z, Scott TR, Oomura Y, Nishino H, Aou S \& Lenard L 1998 Complex functional attributes of amygdaloid gustatory neurons in the rhesus monkey. Annals of the New York Academy of Sciences $\mathbf{8 5 5}$ 488-492.

Karschin C, Dissmann E, Stuhmer W \& Karschin A 1996 IRK(1-3) and GIRK(1-4) inwardly rectifying $\mathrm{K}+$ channel mRNAs are differentially expressed in the adult rat brain. Journal of Neuroscience 16 3559-3570.

Katsuki H, Nakai S, Hirai Y, Akaji K, Kiso Y \& Satoh M 1990 Interleukin-1 beta inhibits long-term potentiation in the CA3 region of mouse hippocampal slices. European Journal of Pharmacology 181 323-326.

Kawakami M \& Kimura F 1975 Acute and chronic effects of the fornix section on cyclic gonadotropin secretion and ovulation in the rat. Endocrinology (Japan) 22 43-48.

Kawakami M, Kubo K, Uemura T, Nagase M \& Hayashi R 1981 Involvement of ovarian innervation in steroid secretion. Endocrinology 109 136-145.

Kay LM \& Feeman WJ 1998 Bidirectional processing in the olfactorylimbic axis during olfactory behavior. Behavioral Neuroscience $\mathbf{1 1 2}$ 541-543.

Kendler HH 1946 The influence of simultaneous hunger and thirst drives upon the learning of two opposed spatial responses of the white rat. Journal of Experimental Psychology 36 212-220.

Kerr DS, Huggett AM \& Abraham WC 1994 Modulation of hippocampal long-term potentiation and long-term depression by corticosteroid receptor activation. Psychobiology 22 123-133.

Kerr JE, Allore RJ, Beck SG \& Handa RJ 1995 Distribution and hormonal regulation of androgen receptor (AR) and AR messenger ribonucleic acid in the rat hippocampus. Endocrinology 136 3213-3221.

Kesner RP 1985 Correspondence between humans and animals in coding of temporal attributes: role of hippocampus and prefrontal cortex. Annals of the New York Academy of Sciences 444 122-136.
Kiefer SW 1985 Neural mediation of conditioned food aversions. Annals of the New York Academy of Sciences 443 100-109.

Kimble DP 1968 Hippocampus and internal inhibition. Psychological Bulletin 70 285-295.

Kimble DP, Bremiller R, Schroeder L \& Smotherman WP 1979 Hippocampal lesions slow extinction of a conditioned taste aversion in rats. Physiology and Behavior 23 217-222.

Klamt JG \& Prado WA 1991 Antinociception and behavioral changes induced by carbachol microinjected into identified sites of the rat brain. Brain Research 549 9-18.

de Kloet ER 1991 Brain corticosteroid receptor balance and homeostatic control. Frontiers in Neuroendocrinology 12 95-164.

de Kloet ER, Vreugdenhil E, Oitzl MS \& Joels M 1998 Brain corticosteroid receptor balance in health and disease. Endocrine Reviews 19 269-301.

Kobayashi T, Ikeda K, Ichikawa T, Abe S, Togashi S \& Kumanishi T 1995 Molecular cloning of a mouse G-protein-activated K+ channel (mGIRK1) and distinct distributions of three GIRK (GIRK1, 2 and 3) mRNAs in mouse brain. Biochemical and Biophysical Research Communications 208 1166-1173.

Kolb B \& Whishaw I 1990 Fundamentals of Human Neuropsychology. New York: WH Freeman.

Komisaruk BR 1970 Synchrony between limbic system activity and rhythmical behavior in rats. Journal of Comparative Physiology and Psychology 70 482-492.

Kosaka K, Taomoto K, Nagatsu I, Heizmann CW, Hunziker W \& Kosaka T 1992 Postnatal X-ray irradiation effects on glomerular layer of rat olfactory bulb: quantitative and immunocytochemical analysis. Experimental Brain Research 90 103-115.

Krane RV, Sinnamon HM \& Thomas GJ 1976 Conditioned taste aversions and neophobia in rats with hippocampal lesions. Journal of Comparative Physiology and Psychology 90 680-693.

Kurihara K \& Kashiwayanagi M 1998 Introductory remarks on umami taste. Annals of the New York Academy of Sciences 855 393-397.

Landin K, Blennow K, Wallin A \& Gottfries CG 1993 Low blood pressure and blood glucose levels in Alzheimer's disease: evidence for a hypometabolic disorder? Journal of Internal Medicine $\mathbf{2 3 3}$ 357-363.

Lapchak PA, Araujo DM, Quirion R \& Beaudet A 1991 Immunoautoradiographic localization of interleukin 2-like immunoreactivity and interleukin 2 receptors (Tac antigen-like immunoreactivity) in the rat brain. Neuroscience 44 173-184.

Lei ZM, Rao CV, Kornyei JL, Licht P \& Hiatt ES 1993 Novel expression of human chorionic gonadotropin/luteinizing hormone receptor gene in brain. Endocrinology 132 2262-2270.

Lenkei Z, Palkovits M, Corvol P \& Llorens-Cortes C 1997 Expression of angiotensin type-1 (AT1) and type-2 (AT2) receptor mRNAs in the adult rat brain: a functional neuroanatomical review. Frontiers in Neuroendocrinology 18 383-439.

Lesniak MA, Hill JM, Kiess W, Rojeski M, Pert CB \& Roth J 1988 Receptors for insulin-like growth factors I and II: autoradiographic localization in rat brain and comparison to receptors for insulin. Endocrinology 123 2089-2099.

Levine S, Coe C \& Wiener SG 1986 Psychoneuroendocrinology of stress: a psychobiological perspective. In Psychoendocrinology, pp 341377. Eds FR Brush \& S Levine. New York: Academic Press.

Li AJ, Katafuchi T, Oda S, Hori T \& Oomura Y 1997 Interleukin-6 inhibits long-term potentiation in rat hippocampal slices. Brain Research 748 30-38.

Li M \& Boyages SC 1996 Detection of extended distribution of B2thyroid hormone receptor messenger ribonucleic acid (RNA) in adult rat brain using complementary RNA in situ hybridization histochemistry. Endocrinology 137 1272-1275.

Lin JH, Way LJ \& Gean PW 1993 Pairing of pre- and postsynaptic activities in hippocampal CA1 neurons induces long-term modifications of NMDA receptor-mediated synaptic potential. Brain Research 603 117-120. 
Lukacs H, Hiatt ES, Lei ZM \& Rao CHV 1995 Peripheral and intracerebroventricular administration of human chorionic gonadotropin alters several hippocampus-associated behaviours in cycling female rats. Hormones and Behavior 29 42-58.

Lupien SJ \& McEwen BS 1997 The acute effects of corticosteroids on cognition: integration of animal and human model studies. Brain Research Reviews 24 1-27.

Lynch KR, Simnad VI, Ben-Ari ET \& Garrison JC 1986 Localization of preangiotensinogen messenger RNA sequences in the rat brain. Hypertension 8 540-543.

McEwen BS 1999 Stress and the aging hippocampus. Frontiers in Neuroendocrinology 20 49-70.

McEwen BS \& Sapolsky RM 1995 Stress and cognitive function. Current Opinion in Neurobiology 5 205-216.

McEwen BS \& Alves SA 1999 Estrogen actions in the central nervous system. Endocrine Reviews 20 279-307.

McGimsey WC, Cidlowski JA, Stumpf WE \& Sar M 1991 Immunocytochemical localization of the glucocorticoid receptor in rat brain, pituitary, liver, and thymus with two new polyclonal antipeptide antibodies. Endocrinology 129 3064-3072.

McGowan-Sass BK \& Timiras PS 1975 The hippocampus and hormonal cyclicity. In The Hippocampus, Vol. 1. Structure and Development, pp 355-391. Eds RL Isaacson \& KH Pribram. New York: Plenum Press.

McGuinness N, Anwyl R \& Rowan M 1991 The effects of external calcium on the $\mathrm{N}$-methyl-D-aspartate induced short-term potentiation in the rat hippocampal slice. Neuroscience Letters 131 13-16.

McKenna JE \& Melzack R 1992 Analgesia produced by lidocaine microinjection into the dentate gyrus. Pain 49 105-112.

MacLean PD 1975 An ongoing analysis of hippocampal inputs and outputs: microelectrode and neuroanatomical findings in squirrel monkeys. In The Hippocampus, Vol. 1: Structure and Development, pp 177-211. Eds RL Isaacson \& KH Pribram. New York: Plenum Press.

Magarinos AM, Ferrini M \& De Nicola AF 1989 Corticosteroid receptors and glucocorticoid content in microdissected brain regions: correlative aspects. Neuroendocrinology 50 673-678.

Magee JC \& Johnston D 1997 A synaptically controlled, associative signal for Hebbian plasticity in hippocampal neurons. Science $\mathbf{2 7 5}$ 209-213.

Maggi A, Susanna L, Bettini E, Mantero G \& Zucchi I 1989 Hippocampus: a target for estrogen action in mammalian brain. Molecular Endocrinology 3 1165-1170.

Mamiya T, Noda Y, Nishi M, Takeshima H \& Nabeshima T 1998 Enhancement of spatial attention in nociceptin/orphanin FQ receptor-knockout mice. Brain Research 783 236-240.

Manabe T, Noda Y, Mamiya T, Katagiri H, Houtani T, Nishi M, Noda T, Takahashi T, Sugimoto T, Nabeshima T et al. 1998 Facilitation of long-term potentiation and memory in mice lacking nociceptin receptors. Nature 394 577-581.

Mares V 1975 An autoradiographic study of regional differences in DNA synthesis in the brains of young adult mice. Acta Histochemica 53 70-76.

Marks JL, Porte DJ, Stahl WL \& Baskin DG 1990 Localization of insulin receptor mRNA in rat brain by in situ hybridization. Endocrinology 127 3234-3236.

Marks JL, Porte D \& Baskin DG 1991 Localization of type I insulinlike growth factor receptor messenger RNA in the adult rat brain by in situ hybridization. Molecular Endocrinology $\mathbf{5} 1158-1167$.

Marr D 1971 Simple memory: a theory for archicortex. Philosophical Transactions of the Royal Society of London 262 23-81.

Martin R, Schwulera U, Menke G, Rudolph W, Buch K, Fasold H, Lissner R, Thrun A, Krauseneck P \& Bogdahn U 1992 Interleukin-2 and blood brain barrier in cats: pharmacokinetics and tolerance following intrathecal and intravenous administration. European Cytokine Network 3 399-406.
Matsumoto K, Ishii N, Yoshida S, Shiosaka S, Wanaka A \& Tohyama M 1998 Molecular cloning and distinct developmental expression pattern of spliced forms of a novel zinc finger gene wiz in the mouse cerebellum. Brain Research. Molecular Brain Research 61 179-189.

Meisenberg G \& Simmons WH 1983 Minireview. Peptides and the blood-brain barrier. Life Sciences 32 2611-2623.

Meunier JC 1997 Nociceptin/orphanin FQ and the opioid receptorlike ORL1 receptor. European Journal of Pharmacology 340 1-15.

Miller JS, Nonneman AJ, Kelly KS, Neisewander JL \& Isaac WL 1986 Disruption of neophobia, conditioned odor aversion, and conditioned taste aversion in rats with hippocampal lesions. Behavioral and Neural Biology 45 240-253.

Miller-Wing AV, Hanesworth JM, Sardinia MF, Hall KL, Wright JW, Speth RC, Grove KL \& Harding JW 1993 Central angiotensin-IV binding sites: distribution and specificity in guinea pig brain. Journal of Pharmacology and Experimental Therapeutics 266 1718-1726.

Milner RJ \& Sutcliffe JG 1983 Gene expression in rat brain. Nucleic Acids Research 11 5497-5520.

Mishkin M 1978 Memory in monkeys severely impaired by combined but not by separate removal of amygdala and hippocampus. Nature 273 297-298.

Miyake A \& Itoh N 1996 Rat fibroblast growth factor receptor-4 mRNA in the brain is preferentially expressed in cholinergic neurons in the medial habenular nucleus. Neuroscience Letters 203 101-104.

Monaghan AP, Bock D, Gass P, Schwager A, Wolfer DP, Lipp HP \& Schutz G 1997 Defective limbic system in mice lacking the tailless gene. Nature 390 515-517.

Monti-Bloch L, Jennings-White C \& Berliner DL 1998 The human vomeronasal system: a review. Annals of the New York Academy of Sciences 855 373-389.

Morris RG 1989 Synaptic plasticity and learning: selective impairment of learning rats and blockade of long-term potentiation in vivo by the N-methyl-D-aspartate receptor antagonist AP5. Journal of Neuroscience 9 3040-3057.

Morris RG, Garrud P, Rawlins JN \& O'Keefe J 1982 Place navigation impaired in rats with hippocampal lesions. Nature 297 681-683.

Morris RG, Anderson E, Lynch GS \& Baudry M 1986 Selective impairment of learning and blockade of long-term potentiation by an $\mathrm{N}$-methyl-D-aspartate receptor antagonist, AP5. Nature 319 774-776.

Moser M \& Moser EI 1998 Functional differentiation in the hippocampus. Hippocampus 8 608-619.

Munck A, Guyre PM \& Holbrook NJ 1984 Physiological functions of glucocorticoids in stress and their relation to pharmacological actions. Endocrine Reviews 5 25-44.

Murphy HM \& Brown TS 1970 Effects of hippocampal lesions on simple and preferential consummatory behaviour in the rat. Journal of Comparative Physiology and Psychology 72 404-415.

Neal CR Jr, Mansour A, Reinscheid R, Nothacker HP, Civelli O, Akil H \& Watson SJ Jr 1999 Opioid receptor-like (ORL1) receptor distribution in the rat central nervous system: comparison of ORL1 receptor mRNA expression with $\left({ }^{125}\right) \mathrm{I}-[(14) \mathrm{Tyr}]$-orphanin FQ binding. Journal of Comparative Neurology 412 563-605.

Nieuwenhuys R, Ten Donkelaar HJ \& Nicholson C 1997 The Central Nervous System of Vertebrates. Berlin: Springer.

Nomoto S, Miyake M, Ohta M, Funakoshi A \& Miyasaka K 1999 Impaired learning and memory in OLETF rats without cholecystokinin (CCK)-A receptor. Physiology and Behavior 66 869-872.

Nyakas CS, de Kloet ER, Veldhuis HD \& Bohus B 1983 Hippocampal corticosterone receptors and novelty-induced behavioural activity: effect of kainic acid lesion in the hippocampus. Brain Research 288 219-228.

O'Keefe J 1979 A review of the hippocampal place cells. Progress in Neurobiology 13 419-439. 
O'Keefe J \& Conway DH 1978 Hippocampal place units in the freely moving rat: why they fire where they fire. Experimental Brain Research 31 573-590.

O’Keefe J \& Nadel L 1978 The Hippocampus as a Cognitive Map. Oxford: Clarendon Press.

Oomura Y, Ono T \& Ooyama H 1970 Inhibitory action of the amygdala on the lateral hypothalamic area in rats. Nature 228 $1108-1110$.

Oomura Y, Sasaki K \& Li A 1993 Memory facilitation educed by food intake. Physiology and Behavior 54 493-498.

Oomura Y, Sasaki K, Li A, Yoshii H, Fukata Y, Yago H, Kimura H, Tooyama I, Hanai K, Nomura Y et al. 1997 aFGF endogenous satiety substance, facilitates learning, memory and immune function in aging. Japan Journal of Physiology 47 52-54.

Orchinik M, Murray TF \& Moore FL 1991 A corticosteroid receptor in neuronal membranes. Science 252 1848-1850.

Osborne B \& Dodek AB 1986 Disrupted patterns of consummatory behaviour in rats with fornix transactions. Behavioral and Neural Biology 45 212-222.

Osborne B \& Flashman LA 1986 Meal patterns following changes in procurement cost for rats with fornix transection. Behavioral and Neural Biology 46 123-136.

Overton DA 1964 State-dependent or 'dissociated' learning produced with pentobarbital. Journal of Comparative Physiology and Psychology 57 3-12.

Palovcik RA, Phillips MI, Kappy MS \& Raizada MK 1984 Insulin inhibits pyramidal neurons in hippocampal slices. Brain Research 309 187-191.

Pardridge WM, Eisenberg J \& Yang J 1985 Human blood-brain barrier insulin receptor. Journal of Neurochemistry 44 1771-1778.

Parker TL, Kesse WK, Mohamed AA \& Afework M 1993 The innervation of the mammalian adrenal gland. Journal of Anatomy 183 265-276.

Pavlides C, Watanabe Y \& McEwen BS 1993 Effects of glucocorticoids on hippocampal long-term potentiation. Hippocampus 3 183-192.

Pavlov IP 1927 Conditioned Reflexes: an Investigation of the Physiological Activity of the Cerebral Cortex. Oxford: Oxford University Press.

Pederson ES, Harding JW \& Wright JW 1998 Attenuation of scopolamine-induced spatial learning impairments by an angiotensin IV analog. Regulatory Peptides 74 97-103.

Pellegrini M, Mansouri A, Simemone A, Boncinelli E \& Gruss P 1996 Dentate gyrus formation requires Emx2. Development 122 3893-3898.

Perrot-Sinal T \& Petersen K 1997 Exposure to predator odor reduces locomotor activity levels in adult male rats: lack of effect of hippocampal lesion. Journal of Chemical Ecology 23 2175-2187.

Petitto JM \& Huang Z 1994 Molecular cloning of a partial cDNA of the interleukin-2 receptor-beta in normal mouse brain: in situ localization in the hippocampus and expression by neuroblastoma cells. Brain Research 650 140-145.

Petitto JM, Huang Z, Raizada MK, Rinker CM \& McCarthy DB 1998 Molecular cloning of the cDNA coding sequence of IL-2 receptor-gamma (gammac) from human and murine forebrain: expression in the hippocampus in situ and by brain cells in vitro. Brain Research. Molecular Brain Research 53 152-162.

Petitto JM, McNamara RK, Gendreau PL, Huang Z \& Jackson AJ 1999 Impaired learning and memory and altered hippocampal neurodevelopment resulting from interleukin-2 gene deletion. Journal of Neuroscience Research 56 441-446.

Piazza PV, Deroche V, Deminiere J, Maccari S, Le Moal M \& Simon H 1993 Corticosterone in the range of stress-induced levels possesses reinforcing properties: implications for sensation-seeking behaviours. PNAS 90 11738-11742.

Pickard BS 1996 Investigations into region-specific and activitydependent gene expression in the mammalian hippocampus. PhD Thesis. University of Edinburgh.
Plata-Salaman CR \& ffrench-Mullen JM 1993 Interleukin-2 modulates calcium currents in dissociated hippocampal CA1 neurons. Neuroreport 4 579-581.

Poduslo JF \& Curran GL 1996 Permeability at the blood-brain and blood-nerve barriers of the neurotrophic factors: NGF, CNTF, NT-3, BDNF. Brain Research. Molecular Brain Research 36 280-286.

Ponce A, Bueno E, Kentros C, Vega-Saenz de Miera E, Chow A, Hillman D, Chen S, Zhu L, Wu MB, Wu X et al. 1996 G-protein-gated inward rectifier $\mathrm{K}+$ channel proteins (GIRK1) are present in the soma and dendrites as well as in nerve terminals of specific neurons in the brain. Journal of Neuroscience 16 1990-2001.

Porter RW 1953 The central nervous system and stress-induced eosinopenia. Recent Progress in Hormone Research 10 1-27.

Prado WA \& Roberts MH 1985 An assessment of the antinociceptive and aversive effects of stimulating identified sites in the rat brain. Brain Research 340 219-228.

Prescott JH, Richardson JT \& Gillespie CR 1990 Cognitive function in diabetes mellitus: the effects of duration of illness and glycaemic control. British Journal of Clinical Psychology 29 167-175.

Racine RJ, Milgram NW \& Hafner S 1983 Long-term potentiation phenomena in the rat limbic forebrain. Brain Research 260 217-231.

Raitiere MN 1992 Proposed role of septohippocampal and pallidohabenulo-raphe systems in photoperiodic time measurement. Medical Hypotheses 38 229-235.

Recce M \& Harris KD 1996 Memory for places: a navigational model in support of Marr's theory of hippocampal function. Hippocampus $\mathbf{6}$ 735-748.

Reed GW, Olson GA \& Olson RD 1994 The Tyr-MIF-1 family of peptides. Neuroscience and Biobehavioral Reviews 18 519-525.

Reilly S, Harley C \& Revusky S 1993 Ibotenate lesions of the hippocampus enhance latent inhibition in conditioned taste aversion and increase resistance to extinction in conditioned taste preference. Behavioral Neuroscience 107 996-1004.

Reinscheid RK, Nothacker HP, Bourson A, Ardati A, Henningsen RA, Bunzow JR, Grandy DK, Langen H, Monsma FJ Jr \& Civelli O 1995 Orphanin FQ: a neuropeptide that activates an opioidlike G protein-coupled receptor. Science 270 792-794.

Richards W 1973 Time reproductions by H.M. Acta Psychologica 79-282.

Risold PY \& Swanson LW 1996 Structural evidence for functional domains in the rat hippocampus. Science 272 1484-1486.

Riss W, Halpern M \& Scalia F 1969 Anatomical aspects of the evolution of the limbic and olfactory systems and their potential significance for behaviour. Annals of the New York Academy of Sciences 159 1096-1111.

Rogers KV, Dunn CK, Hebert SC \& Brown EM 1995 Localization of calcium receptor mRNA in the adult rat central nervous system by in situ hybridization. Brain Research 92 3161-3165.

Rose KA, Stapleton G, Dott K, Kieny MP, Best R, Schwarz M, Russell DW, Björkheim I, Seckl JR \& Lathe R 1997 Cyp7b hydroxylates dehydroepiandrosterone (DHEA) and pregnenolone at the 7 alpha position. PNAS 94 4925-4930.

Ruat M, Molliver ME, Snowman AM \& Snyder SH 1995 Calcium sensing receptor: molecular cloning in rat and localization to nerve terminals. PNAS 92 3161-3165.

Ruit KG \& Neafsey EJ 1988 Cardiovascular and respiratory responses to electrical and chemical stimulation of the hippocampus in anesthetized and awake rats. Brain Research 457 310-321.

Saito H, Kaba H, Sato T, Honmura A, Kawakami T, Seto K, Yamamoto H \& Kawakami M 1989 Influence of electrical stimulation of the limbic structure on adrenocortical steroidogenesis in hypophysectomized rats. Experimental and Clinical Endocrinology 94 387-390.

Saito H, Kaba H, Sato T, Nojima K, Li CS, Seto K, Kimura F \& Kawakami M 1990 Influence of dorsal hippocampal stimulation and dorsal fornix lesions on hepatic glucose metabolism in rabbits. Experimental and Clinical Endocrinology 96 113-116. 
Sakiyama Y, Sato A, Senda M, Ishiwata K, Toyama H \& Schmidt RF 1998 Positron emission tomography reveals changes in global and regional cerebral blood flow during noxious stimulation of normal and inflamed elbow joints in anesthetized cats. Experimental Brain Research 118 439-446.

Sandin J, Georgieva J, Schott PA, Ogren SO \& Terenius L 1997 Nociceptin/orphanin FQ microinjected into hippocampus impairs spatial learning in rats. European Journal of Neuroscience 9 194-197.

Sanes JR \& Lichtman JW 1999 Can molecules explain long-term potentiation? Nature Neuroscience 2 597-604.

Sapolsky RM 1985 Glucocorticoid toxicity in the hippocampus: temporal aspects of neuronal vulnerability. Brain Research 359 300-305.

Sapolsky RM, Krey LC \& McEwen BS 1986 The neuroendocrinology of stress and aging: the glucocorticoid cascade hypothesis. Endocrine Reviews 7 284-301.

Sapolsky RM, Stein-Behrens BA \& Armanini MP 1991 Long-term adrenalectomy causes loss of dentate gyrus and pyramidal neurons in the adult hippocampus. Experimental Neurology 114 246-249.

Sar M, Lubahn DB, French FS \& Wilson EM 1990 Immunohistochemical localization of the androgen receptor in rat and human tissues. Endocrinology 127 3180-3186.

Sarnat HB \& Netsky MG 1974 Evolution of the Nervous System. New York: Oxford University Press.

Sawada S, Yamamoto C \& Ohno-Shosaku T 1994 Long-term potentiation and depression in the dentate gyrus, and effects of nicotine. Neuroscience Research 20 323-329.

Schnitzlein HN 1966 The primordial amygdaloid complex of the African lungfish, Protopterus. In Evolution of the Forebrain; Phylogenesis and Ontogenesis of the Forebrain, pp 40-53. Eds R Hassler \& H Stephan. Stuttgart: Georg Thième.

Schöbitz B, de Kloet ER, Sutanto W \& Holsboer F 1993 Cellular localization of interleukin $6 \mathrm{mRNA}$ and interleukin 6 receptor mRNA in rat brain. European Journal of Neuroscience 5 1426-1435.

Scoville WB \& Milner B 1957 Loss of recent memory after bilateral hippocampal lesions. Journal of Neurology, Neurosurgery and Psychiatry 21 11-21.

Seckl JR, Dickson KL, Yates C \& Fink G 1991 Distribution of glucocorticoid and mineralocorticoid receptor messenger RNA expression in human postmortem hippocampus. Brain Research 561 332-337.

Seto K, Saito H, Kaba H, Honmura A, Li CS, Nakagawa M, Ikeda H \& Kawakami M 1988 Influence of electrical stimulation of the limbic structure on ovarian steroidogenesis in hypophysectomized and adrenalectomized rats. Experimental and Clinical Endocrinology 91 235-237.

Shimohigashi Y, Hatano R, Fujita T, Nakashima R, Nose T, Sujaku T, Saigo A, Shinjo K \& Nagahisa A 1996 Sensitivity of opioid receptor-like receptor ORL1 for chemical modification on nociceptin, a naturally occurring nociceptive peptide. Journal of Biological Chemistry 271 23642-23645.

Shoaib M \& Stolerman IP 1996 Brain sites mediating the discriminative stimulus effects of nicotine in rats. Behavioural Brain Research 78 183-188.

Shors TJ, Levine S \& Thompson RF 1990 Effect of adrenalectomy and demedullation on the stress-induced impairment of long-term potentiation. Neuroendocrinology 51 70-75.

Shughrue PJ, Lane MV \& Merchenthaler I 1997a Comparative distribution of estrogen receptor-alpha and -beta mRNA in the rat central nervous system. Journal of Comparative Neurology 388 507-525.

Shughrue P, Scrimo P, Lane M, Askew R \& Merchenthaler I 1997 b The distribution of estrogen receptor-beta mRNA in forebrain regions of the estrogen receptor-alpha knockout mouse. Endocrinology 138 5649-5652.

Shughrue PJ, Scrimo PJ \& Merchenthaler I 1998 Evidence for the colocalization of estrogen receptor-beta mRNA and estrogen receptor-alpha immunoreactivity in neurons of the rat forebrain. Endocrinology 139 5267-5270.
Sloviter RS, Valiquette G, Abrams GM, Ronk EC, Sollas AL, Paul LA \& Neubort S 1989 Selective loss of hippocampal granule cells in the mature rat brain after adrenalectomy. Science 243 535-538.

Smith DA, Browning M \& Dunwiddie TV 1993 Cocaine inhibits hippocampal long-term potentiation. Brain Research 608 259-265.

Smotherman WP, Kolp LA, Coyle S \& Levine S 1981 Hippocampal lesion effects on conditioned taste aversion and pituitary-adrenal activity in rats. Behavioural Brain Research 2 33-48.

Sobel N, Prabhakaran V, Hartley CA, Desmond JE, Glover GH, Sullivan EV \& Gabrieli JD 1999 Blind smell: brain activation induced by an undetected air-borne chemical. Brain 122 209-217.

Song C \& Leonard BE 1995 Interleukin-2-induced changes in behavioural, neurotransmitter, and immunological parameters in the olfactory bulbectomized rat. Neuroimmunomodulation 2 263-273.

Soosar A, Chiaramello A, Zuber MX \& Neuman T 1994 Expression of basic-helix-loop-helix transcription factor ME2 during brain development and in the regions of neuronal plasticity in the adult brain. Molecular Brain Research 25 176-180.

Squire LR 1992 Memory and the hippocampus: a synthesis from findings with rats, monkeys, and humans. Psychological Review 99 195-231.

Squire LR \& Moore RY 1979 Dorsal thalamic lesion in a noted case of human memory dysfunction. Annals of Neurology 6 503-506.

Squire LR \& Zola-Morgan S 1991 The medial temporal lobe memory system. Science 253 1380-1386.

Squire LR, Shimamura AP \& Amaral DG 1989 Memory and the hippocampus. In Neural Models of Plasticity, pp 208-239. Eds J Byrne \& WO Berry. New York: Academic Press.

Stapleton G, Steel M, Richardson M, Mason JO, Rose KA, Morris RG \& Lathe R 1995 A novel cytochrome P450 expressed primarily in brain. Journal of Biological Chemistry 270 29739-29745.

Steel M, Moss J, Clark KA, Kearns IR, Davies CH, Morris RG, Skarnes WC \& Lathe R 1998 Gene-trapping to identify and analyze genes expressed in the mouse hippocampus. Hippocampus $\mathbf{8}$ $444-457$.

Stepien L \& Sierpinski S 1964 Impairment of recent memory after temporal lesions in man. Neuropsychologia 2 291-303.

Stringer JL, Greenfield LJ, Hackett JT \& Guyenet PG 1983 Blockade of long-term potentiation by phencyclidine and sigma opiates in the hippocampus in vivo and in vitro. Brain Research 280 127-138.

Strong AJ, Fairfield JE, Monteiro E, Kirby M, Hogg AR, Snape M \& Ross-Field L 1990 Insulin protects cognitive function in experimental stroke. Journal of Neurology, Neurosurgery and Psychiatry 53 847-853.

Sudilovsky A, Turnbull B, Croog SH \& Crook T 1988 Angiotensin converting enzyme and memory: preclinical and clinical data. International Journal of Neurology 21 144-163.

Suhonen JO, Peterson DA, Ray J \& Gage FH 1996 Differentiation of adult hippocampus-derived progenitors into olfactory neurons in vivo. Nature 383 624-627.

Sutanto W, Van Eekelen JA, Reul JM \& de Kloet ER 1988 Speciesspecific topography of corticosteroid receptor types in rat and hamster brain. Neuroendocrinology 47 398-404.

Swanson LW 1991 Biochemical switching in hypothalamic circuits mediating responses to stress. Progress in Brain Research 87 181-200.

Swanson LW \& Petrovich GD 1998 What is the amygdala? Trends in Neurosciences 21 323-331.

Takao T, Culp SG, Newton RC \& De Souza EB 1992 Type 1 interleukin-1 receptors in the mouse brain-endocrine-immune axis labelled with $\left[{ }^{125} \mathrm{I}\right]$ recombinant human interleukin-1 receptor antagonist. Neuroimmunology 41 51-60.

Talamo BR, Rudel R, Kosik KS, Lee VM, Neff S, Adelman L \& Kauer JS 1989 Pathological changes in olfactory neurons in patients with Alzheimer's disease. Nature 337 736-739.

Tancredi V, Zona C, Velotti F, Eusebi F \& Santoni A 1990 Interleukin-2 suppresses established long-term potentiation and inhibits its induction in the rat hippocampus. Brain Research $\mathbf{5 2 5}$ 149-151. 
Terzian H \& Dalle Ore G 1955 Syndrome of Klüver and Bucy reproduced in man by bilateral removal of the temporal lobes. Neurology 5 373-380.

Teuber H, Milner B \& Vaughan Jr HG 1968 Persistent anterograde amnesia after stab wound of the basal brain. Neuropsychologia $\mathbf{6}$ 267-282.

Thompson MD, Knee K \& Golden CJ 1998 Olfaction in persons with Alzheimer's disease. Neuropsychological Review 8 11-23.

Tindal JS \& Blake LA 1984 Central inhibition of milk ejection in the rabbit: involvement of hippocampus and subiculum. Journal of Endocrinology 100 125-129.

Tiong AH \& Richardson JS 1990 Differential effects of olfactory bulbectomy on beta-adrenoceptors in rat amygdala, hippocampus and cerebral cortex. Brain Research 531 269-275.

Toth P, Lukacs H, Hiatt ES, Reid KH, Iyer V \& Rao CHV 1994 Administration of human chorionic gonadotropin affects sleep-wake phases and other associated behaviours in cycling female rats. Brain Research 654 181-190.

Tulving E \& Markowitsch HJ 1998 Episodic and declarative memory: role of the hippocampus. Hippocampus 8 198-204.

Van Eekelen JA \& de Kloet ER 1992 Co-localization of brain corticosteroid receptors in the rat hippocampus. Progress in Histochemistry and Cytochemistry 26 250-258.

Van Hartesvelt C 1975 The hippocampus and regulation of the hypothalamic-hypophyseal-adrenal cortical axis. In The Hippocampus, Vol. 1, Structure and Development, pp 375-391. Eds RL Isaacson \& KH Pribram. New York: Plenum Press.

Van de Kar LD \& Blair ML 1999 Forebrain pathways mediating stress-induced hormone secretion. Frontiers in Neuroendocrinology 20 $1-48$.

Vanhanen M \& Soininen H 1998 Glucose intolerance, cognitive impairment and Alzheimer's disease. Current Opinion in Neurology 11 673-677.

Versteeg CA, De Jong W \& Bohus B 1984 Arginine-vasopressin inhibits centrally induced pressor responses by involving hippocampal mechanisms. Brain Research 292 317-326.

Waguespack PJ, Banks WA \& Kastin AJ 1994 Interleukin-2 does not cross the blood-brain barrier by a saturable transport system. Brain Research Bulletin 34 103-109.

Walker LG, Wesnes KP, Heys SD, Walker MB, Lolley J \& Eremin O 1996 The cognitive effects of recombinant interleukin-2 (rIL-2) therapy: a controlled clinical trial using computerised assessments. European Journal of Cancer 32A 2275-2283.

Wang JQ \& Ingenito AJ 1994 Cardiovascular effects of microinjection of dynorphin-a(1-8) into the hippocampus in conscious, spontaneously hypertensive and normotensive Wistar-Kyoto rats. Clinical and Experimental Hypertension 16 229-243.

Wayner MJ, Armstrong DL, Polan-Curtain JL \& Denny JB 1993 Role of angiotensin II and AT1 receptors in hippocampal LTP. Pharmacology, Biochemistry and Behavior 45 455-464.

Wayner MJ, Chitwood R, Armstrong DL \& Phelix C 1997 Ethanol affects hypothalamic neurons projecting to the hippocampus and inhibits dentate granule cell LTP. Alcohol 14 1-7.

Wehling M, Christ M \& Gerzer R 1993 Aldosterone-specific membrane receptors and related rapid, non-genomic effects. Trends in Pharmacological Science 14 1-4.

Weingartner H \& Faillace LA 1971 Alcohol state-dependent learning in man. Journal of Nervous and Mental Disease 153 395-406.

Weyhenmeyer JA \& Phillips MI 1982 Angiotensin-like immunoreactivity in the brain of the spontaneously hypertensive rat. Hypertension 4 514-523.

Williams LM, Adam CL, Mercer JG, Moar KM, Slater D, Hunter L, Findlay PA \& Hoggard N 1999 Leptin receptor and neuropeptide $\mathrm{Y}$ gene expression in the sheep brain. Journal of Neuroendocrinology 11 165-169.
Willis WD \& Westlund KN 1997 Neuroanatomy of the pain system and of the pathways that modulate pain. Journal of Clinical Neurophysiology 14 2-31.

Willshaw DJ \& Buckingham JT 1990 An assessment of Marr's theory of the hippocampus as a temporary memory store. Philosophical Transactions of the Royal Society of London 329 205-215.

Wolf G \& Neilson EG 1992 Effects of angiotensin II on proximal tubular cells stably transfected with the c-mas oncogene. American Journal of Physiology 263 F931-F938.

Wong M \& Licinio J 1994 Localization of interleukin 1 type I receptor mRNA in rat brain. Neuroimmunomodulation 1 110-115.

Wright JW \& Harding JW 1997 Important roles for angiotensin III and IV in the brain renin-angiotensin system. Brain Research Reviews 25 96-124.

Wright JW, Miller-Wing AV, Shaffer MJ, Higginson C, Wright DE, Hanesworth JM \& Harding JW 1993 Angiotensin II(3-8) (ANG IV) hippocampal binding: potential role in the facilitation of memory. Brain Research Bulletin 32 497-502.

Wyszynski M, Lin J, Rao A, Nigh E, Beggs AH, Craig AM \& Sheng M 1997 Competitive binding of alpha-actinin and calmodulin to the NMDA receptor. Nature 385 439-442.

Yamamoto T 1993 Neural mechanisms of taste aversion learning. Neuroscience Research 16 181-185.

Yamamoto T \& Fujimoto Y 1991 Brain mechanisms of taste aversion learning in the rat. Brain Research Bulletin 27 403-406.

Yamamoto T, Fujimoto Y, Shimura T \& Sakai N 1995 Conditioned taste aversion in rats with excitotoxic brain lesions. Neuroscience Research 22 31-49.

Yazaki N, Hosoi Y, Kawabata K, Miyake A, Minami M, Satoh M, Ohta M, Kawasaki T \& Itoh N 1994 Differential expression patterns of mRNAs for members of the fibroblast growth factor receptor family, FGFR-1-FGFR-4, in rat brain. Journal of Neuroscience Research 37 445-452.

Yoshida M, Suda Y, Matsuo I, Miyamoto N, Takeda N, Kuratani S \& Aizawa S 1997 Emx1 and Emx2 functions in development of dorsal telencephalon. Development 124 101-111.

Yousem DM, Geckle RJ, Bilker WB \& Doty RL 1998 Olfactory bulb and tract and temporal lobe volumes: normative data across decades. Annals of the New York Academy of Sciences 855 546-555.

Yu TP, Fein J, Phan T, Evans CJ \& Xie CW 1997 Orphanin FQ inhibits synaptic transmission and long-term potentiation in rat hippocampus. Hippocampus 7 88-94.

Zheng J \& Ramirez VD 1997 Demonstration of membrane estrogen binding proteins in rat brain by ligand blotting using a 17 beta-estradiol- $\left[{ }^{125} \mathrm{I}\right]$ bovine serum albumin conjugate. Journal of Steroid Biochemistry and Molecular Biology 62 327-336.

Zlokovic BV, Hyman S, McComb JG, Lipovac MN, Tang G \& Davson H 1990a Kinetics of arginine-vasopressin uptake at the blood-brain barrier. Biochimica et Biophysica Acta 1025 191-198.

Zlokovic BV, Skundric DS, Segal MB, Lipovac MN, Mackic JB \& Davson H $1990 b$ A saturable mechanism for transport of immunoglobulin $\mathrm{G}$ across the blood-brain barrier of the guinea pig. Experimental Neurology 107 263-270.

Zola-Morgan S, Squire LR, Alvarez-Royo P \& Clower RP 1991 Independence of memory functions and emotional behavior: separate contributions of the hippocampal formation and the amygdala. Hippocampus 1 207-220.

Received 22 May 2000

Received in final form 17 January 2001

Accepted 31 January 2001 